\title{
Climate Change Hotspots Mapping: What Have We Learned?
}

\author{
Alex de Sherbinin \\ Senior Research Associate \\ CIESIN, Columbia University \\ PO Box 1000 \\ Palisades NY 10964 USA \\ Email: adesherbinin@ciesin.columbia.edu \\ Tel. +1-845-365-8936 \\ Fax: +1-845-365-8922
}

\begin{abstract}
In the past five years there has been a proliferation of efforts to map climate change "hotspots" regions that are particularly vulnerable to current or future climate impacts, and where human security may be at risk. While some are academic exercises, many are produced with the goal of drawing policy maker attention to regions that are particularly susceptible to climate impacts, either to mitigate the risk of humanitarian crises or conflicts or to target adaptation assistance. Hotspots mapping efforts address a range of issues and sectors such as vulnerable populations, humanitarian crises, conflict, agriculture and food security, and water resources. This paper offers a timely assessment of the strengths and weaknesses of current hotspots mapping approaches with the goal of improving future efforts. It also highlights regions that are anticipated, based on combinations of high exposure, high sensitivity and low adaptive capacity, to suffer significant impacts from climate change.
\end{abstract}

Keywords: hotspots, spatial vulnerability assessment, climate impacts

Note: This is an unformatted post-print version of the article. The final published version of this paper in Climatic Change is available at http://dx.doi.org/10.1007/s10584-013-0900-7 or via http://link.springer.com/. 


\section{Contents}

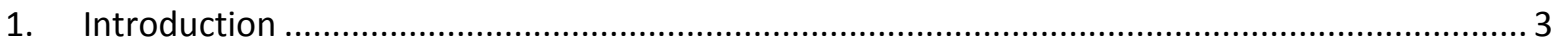

2. Common Conceptual, Data and Methodological Issues .......................................................... 3

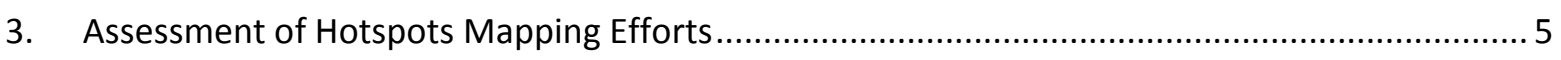

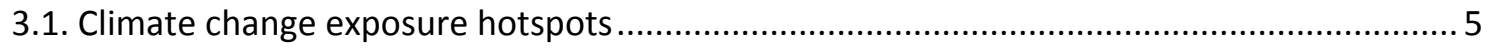

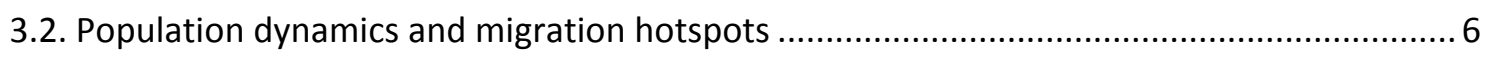

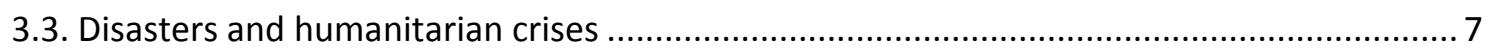

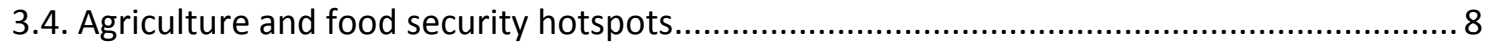

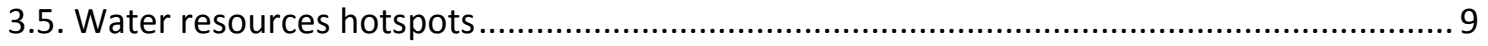

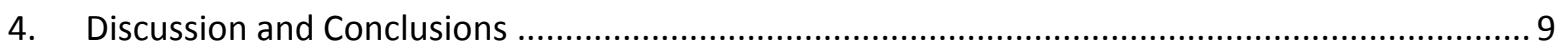

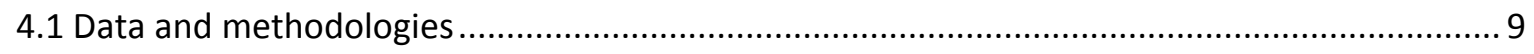

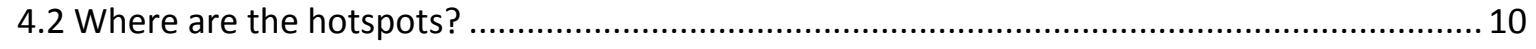

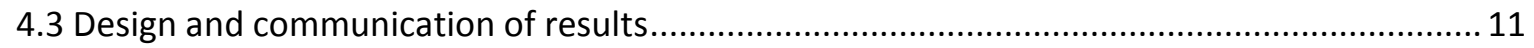

4.4 Hotspots maps as tools for decision making ................................................................... 11

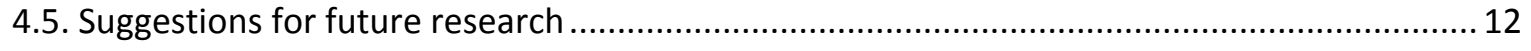

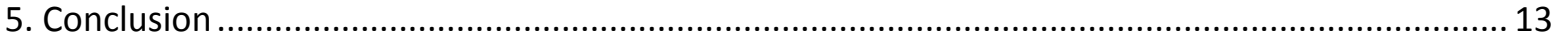

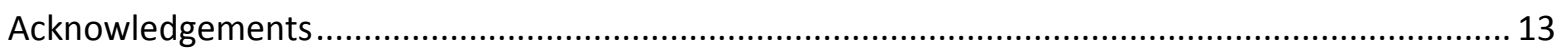

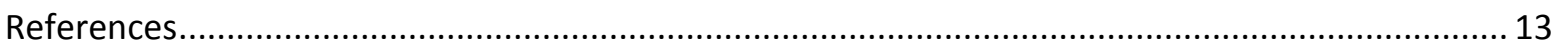

Supplementary Online Material - Climate Change Hotspots Mapping ............................................. 17

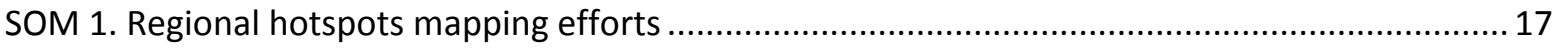

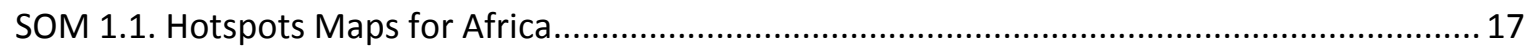

SOM 1.2. Hotspots Map for Southeast Asia ............................................................................... 19

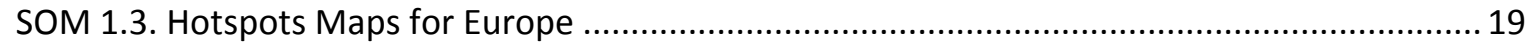

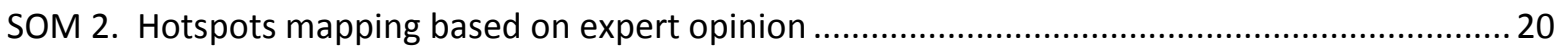

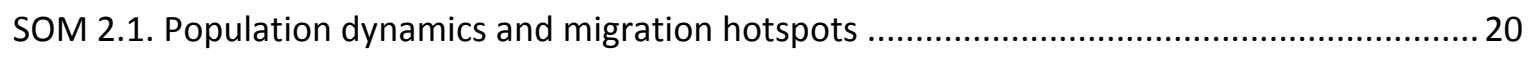

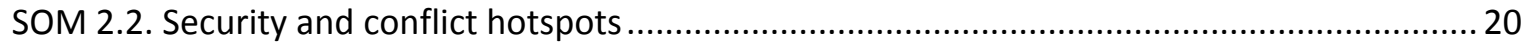

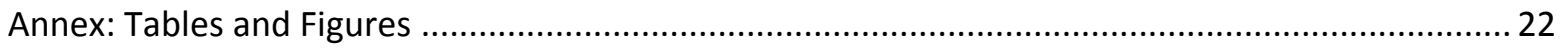




\section{Introduction}

Maps depicting climate change "hotspots" have been issued with increasing regularity in recent years by researchers, advocacy groups, and NGOs. By identifying likely climate change impacts and conveying them in a map format with strong visual elements, hotspots maps can help to communicate issues in a manner that may be easier to interpret than text. Hotspots maps are developed with a number of goals in mind. Academic researchers are generally seeking to vet data and methodologies, applied researchers may be interested in guiding institutional strategies, and NGOs are often communicating climate impacts. In addition, building on early roots in biodiversity hotspots mapping (Myers 1990) where hotspots were developed to target conservation efforts, hotspots maps are often explicitly developed to help aid organizations in priority setting and strategic planning with regards to climate adaptation projects (Kok et al. 2011; Midgley et al. 2011; Yusuf and Francisco 2009). At a time of increasing pressure on donors and development organizations to show that scarce public resources are being used in a responsible manner, spatial indicators and hotspots maps hold the promise of transparent, "scientific", and defensible priority setting (Barnett et al. 2008). Although hotspots mapping holds great promise for informing policy, there are a number of risks as well, which are reviewed in the discussion section. This paper offers a timely assessment of the strengths and weaknesses of current hotspots mapping approaches with the goal of improving future efforts. It also highlights regions that are anticipated, based on combinations of high exposure, high sensitivity and low adaptive capacity, to suffer significant impacts from climate change.

This review focuses on global data-driven GIS or modeling approaches to hotspots identification. Unlike national level hotspots mapping, these efforts capture subnational variation in vulnerability by combining spatial data layers, generally by converting each layer to a unitless scale and aggregating the layers to reveal vulnerability levels. In this approach, hotspots emerge from the spatial analysis, being revealed through the integration of spatial layers. In the supplementary online material (SOM) I also review several regional GIS-based and global expert-based hotspots mapping efforts.

I exclude from this review hotpots mapping efforts that use countries as the units of analysis, since these are essentially repackaging of country level indicators (e.g., Birkmann et al. 2011; Yohe et al. 2006), with all the limitations inherent in those approaches (Barnett et al. 2008). I also limit this review to mapping efforts whose primary goal is explicitly to identify hotspots or geographic areas where impacts will be greatest (even if not labeled per se as hotspots), rather than maps describing impacts that are incidental to a publication or report.

Papers meeting these criteria were identified through Google Scholar searches on "climate change hotspots" and "hot spots", announcements, and bibliographies of other spatial vulnerability assessment reviews. This paper identifies some common conceptual, data and methodological issues (Section 2); and then moves to a review of hotspots mapping efforts in the two broad classes (Section 3). It then proceeds to discussion (Section 4) and conclusions (Section 5).

\section{Common Conceptual, Data and Methodological Issues}

Hotspots mapping efforts can be divided into three broad categories: those based solely on climate parameters, those that portray patterns of societal vulnerability to climate change impacts, and those that seek to portray impacts on particular systems, such as agriculture or water. Of the three, 
vulnerability mapping is the most common, and also the most conceptually challenging owing to the proliferation of frameworks and definitions (Eakin and Luers 2006; Adger 2006). O'Brien et al. (2007) describe two broad categories of vulnerability definitions, one that identifies contextual vulnerability or the intrinsic characteristics of a system, which is rooted in political economy, and another, outcome vulnerability, which combines information on potential climate impacts and on the capacity of society to cope and adapt. Vulnerability hotspots mapping efforts generally adopt the latter, which is closer to the IPCC definition of vulnerability as a function of exposure, sensitivity, and coping capacity (Parry et al. 2007). While there is no one correct way to characterize vulnerability, there are certainly wrong ways to do so. Füssel (2007) argues that quantitative vulnerability assessment requires definition of the system of analysis (what is vulnerable?), the valued attributes of concern (why is it important?), the external hazard (to what is the system vulnerable?), and a temporal reference (when?).

Beyond conceptual definitions and frameworks, there are significant measurement challenges (Birkmann and Wisner 2006). The exposure aspect of vulnerability generally presents fewer problems, since biophysical data sets are reasonably well advanced, and the uncertainties in the data are, for the most part, quantifiable. However, owing to data gaps, the socioeconomic aspects are often measured through the use of proxies. Thus for sensitivity it is common to use close surrogates such as poverty levels and income, and for coping or adaptive capacity, measures might include education, institutional capacity, funding levels for disaster risk reduction, or insurance coverage. These are often less-thanadequate proxies for intrinsic vulnerability, and many of them are difficult to measure or data may be difficult to obtain. As Kasperson et al. (2005: 149) write, "political and social marginalization, gendered relationships, and physiological differences are commonly identified variables influencing vulnerability, but incorporating this conceptual understanding in global mapping remains a challenge."

Not all hotspots mapping efforts actually incorporate future climate change and variability. Some use past variability or extreme events as a proxy for future changes. However, those that do use general circulation model (GCM) outputs run into a number of issues. A fundamental challenge for vulnerability mapping that relies on accurate prediction of extremes, such as that for hazards or human vulnerability, is the limited ability of GCMs to capture historical variance or future extremes (IPCC 2012; Brown \& Wilby 2012). The use of multi-model ensembles only tends to further reduce variance. The spatial resolution of the model outputs - ranging in resolution from 1 to 2 degree grid cells - is also a concern, and some efforts do not follow the best practice of using multiple models for a given SRES scenario.

Specific climate parameters that are required will differ based on the kind of hotspots assessment. For agricultural systems, water management, or natural hazard prediction, the most important variables would be anticipated change in rainy season onset, gaps in rainfall during growing seasons, changes in drought periodicity, changes in rainfall duration and intensity, and temperature increases beyond certain crop thresholds. These parameters are not easy to calculate, so hotspots efforts require a certain amount of expertise in climate data analysis. Although GCM outputs have uncertainties, it should be noted that hotspots mapping efforts that rely on long-term precipitation reanalysis data are also inaccurate in some regions, especially in developing countries where there is sparse rain gauge data.

Finally, Preston et al. (2011) highlight a number of temporal and scale issues that tend to plague vulnerability mapping. Often data layers are from inconsistent dates, scale mismatches in underlying data sets create spatial artifacts in the maps, and for mapping efforts that do use GCM outputs, the 
Revised Accepted Manuscript submitted to Climatic Change (8 August 2013).

sensitivity and adaptive capacity variables represent current rather than future states. These issues are addressed again below.

\section{Assessment of Hotspots Mapping Efforts}

In this section I review a range of hotspots mapping efforts covering broad vulnerability themes, assessing methods, strengths and weaknesses, and commonly identified regions. Table 1 provides a summary list of the studies and, to the extent provided in the reports, identifies important components of quantitative vulnerability per Füssel (2007). This table also includes studies described in the SOM. Map figures for all studies are included in the SOM, along with a table that summarizes each study's primary focus, audience, geographic scope, framework, methods, regions identified as most at risk from climate impacts, and funding sources.

\subsection{Climate change exposure hotspots}

There is a subset of hotspots mapping efforts that focus only on projected changes in temperature and selected precipitation parameters, that is, the "exposure" part of the IPCC formulation. Giorgi's (2006) Regional Climate Change Index ( $\mathrm{RCCl}$ ) was the first to depict climate hotspots based solely on climate model outputs. The RCCl is measures changes by 2080-99 against a baseline of 1960-79 in regional mean precipitation, mean surface air temperature, and in the interannual variability in precipitation and temperature. Giorgi uses a multi-model ensemble across a range of IPCC scenarios (A1B, B1, and A2) to define changes. The $\mathrm{RCCl}$ is a comparative index designed to identify the regions that will see the greatest relative changes in these variables, which are identified as hotspots. Note that a small RCCI value does not imply a small absolute change, but only a small climate response compared to other regions. The $\mathrm{RCCl}$ is calculated for 26 land regions (not on a pixel basis) from a set of climate change projections by 20 global climate models for the A1B, A2 and B1 IPCC emission scenarios.

The "hottest" hotspots are those in northern latitudes, which are predicted to experience the greatest temperature changes (Figure 1). The two most prominent hotspots are the Mediterranean, which will see declines in mean precipitation, and North Eastern Europe, which will see increases in winter precipitation and a strong regional warming relative to the global mean. Central America is the main tropical hotspot, which is predicted to see a decrease in precipitation and an increase in precipitation variability, followed by southern Africa. The global RCCl is limited by the representation of the hotspots (broad regions) and the fact that change measurements are bi-directional, and thus a strong increase in precipitation, which could be viewed as positive for some regions, is seen as equally problematic as a strong decrease in precipitation. On its own, the index says very little about vulnerability per se, but it has been applied together with socioeconomic indicators to identify socioclimatic hotspots in Brazil (Torres et al. 2012), and a similar approach was used to map hotspots in the U.S. (Diffenbaugh et al. 2006).

Baettig et al. (2007) introduced a Climate Change Index (CCl) which seeks to measure the strength of future climate change relative to today's natural variability. The index tracks increases in the probabilities of such events relative to a 1 in 20 year return cycle for the same events under current climatology. It is calculated based on GCMs running SRES A2 and B2 scenarios, with indicators such as additional hottest years, additional driest years, and additional extremely warm/wet/dry seasons (winter and summer months). According to the $\mathrm{CCl}$, the largest changes in frequency will occur in the 
Revised Accepted Manuscript submitted to Climatic Change (8 August 2013).

tropics and high latitudes. The $\mathrm{CCl}$ has the advantage that results are presented on a pixel basis, and they are also summarized by country for the benefit of policy audiences, and the scores are also relatively easy to interpret. The $\mathrm{CCl}$ depicts similar hotspots to the $\mathrm{RCCl}$, except for northern southern Africa and the Amazon, which are found to have much greater exposure to climate risks when compared to the present (Figure 2).

The $\mathrm{RCCl}$ and $\mathrm{CCl}$ contribute to the literature by describing changes to climate parameters that could serve as inputs to broader vulnerability assessments. However, despite claims to the contrary, both are clearly for academic audiences. By contrast, the UK Met Office has produced a map depicting the regional temperature changes associated with a $4^{\circ} \mathrm{C}$ rise in global mean temperature (Figure 3 ). The map, produced in poster and online interactive forms, is intended for policy audiences, utilizing circles of various colors to highlight likely impacts. Areas with the greatest temperature changes include the Arctic and high northern latitudes, the western US, the Amazon, West Africa, southern Africa, and Central Asia.

A hybrid approach, based on climate parameters but tied to thresholds in four important sectors (water, agriculture, ecosystems and health), was recently developed by Piontek et al. (2013). The authors use the outputs of three GCMs simulating the highest representative concentration pathway (RCP8.5) to feed multiple Global Impact Models (GIMs), and then identify temperature thresholds in each sector where impacts could be considered to be severe. For example, the thresholds for the water and agriculture sectors are defined as the $10^{\text {th }}$ percentile of the reference period distribution (19802010) of river discharge and crop yields, respectively. For each GIM-GCM combination and at each grid cell they define a "crossing temperature" that is the global mean temperature change (GMT $\Delta$ ) at which the sectoral metric crosses the respective impact threshold. Hotspot regions where thresholds are crossed for two or three sectors for a $4.5^{\circ} \mathrm{C} \mathrm{GMT} \Delta$ are found in Figure 4, with high impacts found in the Amazon, the Andes, southern Mexico and Central America, southern and eastern Europe, the African highlands and parts of West Africa, and the Ganges basin. These results should be seen as conservative, given the stringent criteria for inclusion of severe impacts ( $>50 \%$ of GIM-GCM combinations agreeing) used in the study.

\subsection{Population dynamics and migration hotspots}

There has been considerable policy interest in the impact of climate change on population dynamics, and particularly on migration (Black et al. 2011; de Sherbinin et al. 2011). This has spawned a number of efforts to map hotspots where climate change may affect population dynamics or lead to migration flows.

Samson et al. (2011) use the relationship between the distribution of human population density and climate as a basis to develop a global index of predicted impacts of climate change on human populations. The authors use an ecological niche model that identifies current population distribution in relationship to climate conditions, and then identifies how climate conditions may change in ways that they no longer support current densities. Their climate vulnerability index (CVI) combines regional climate-density relationships with predicted regional climate change. The climate variables that were found to have the highest predictive power for current population densities, and which were therefore used to determine areas of decline, include $(A)$ annual mean temperature $\left({ }^{\circ} \mathrm{C}\right)$, (B) mean temperature diurnal range $\left({ }^{\circ} \mathrm{C}\right),(\mathrm{C})$ total annual precipitation $(\mathrm{mm})$, and $(\mathrm{D})$ precipitation seasonality (coefficient of variation). 
Revised Accepted Manuscript submitted to Climatic Change (8 August 2013).

A second climate-demography vulnerability index (CDVI) adds a third dimension, rapid population growth, to shows areas in which conditions that already support high population densities and where there is rapid population growth will see a decline in climate conditions. The authors ran their model using several climate projections. Figures 5 and 6 show the resulting maps. For the CVI, hotspots of high vulnerability are found in the Amazon basin, North Africa, Sudan, southern Africa, Central China, Mongolia, and eastern Australia. For the CDVI, the same regions become "hotter", while new areas are added in Central America, the U.S. Southwest, most of Africa, the Arabian Peninsula, Afghanistan, and Indonesia. Many of these are areas where climate change will amplify the conditions currently supporting low population densities, e.g., hot and arid regions that will become drier. Yet the CDVI clearly identifies a number of tropical humid regions (Amazon, Central Africa, and Indonesia) as hotspots as well. One limitation is the treatment of populations as homogenous, and therefore having similar sensitivity and adaptive capacity to climate change impacts.

A number of efforts have sought to identify hotspots of population vulnerability to sea level rise (SLR). Here I review a representative global assessment by McGranahan et al. (2007), which utilizes a Low Elevation Coastal Zone (LECZ) mask, representing coastal elevations from 0-10m, to identify the regions that will be most affected by climate change impacts. Results are provided in spatial and tabular formats, providing estimates of population exposure within the LECZ for urban and rural areas by country. The method constitutes a simple overlay of the LECZ grid on a year 2000 population grid. The maps identify highly populated areas at high risk of coastal flooding and SLR, especially the Asian "megadeltas" (Figure 7). The strength of this effort is that the methodology is simple and easy to understand, and the impacts of SLR are relatively certain, though the timing of specific sea level increments is a matter of some debate, and local impacts are hard to predict with global scale data sets.

\subsection{Disasters and humanitarian crises}

It is widely recognized that the greatest impacts of climate change will not necessarily be the result of secular changes in temperature and precipitation over decades, but rather will be the result of shortterm variability and extremes (IPCC 2012). Important mapping efforts have been conducted by the World Bank (Dilley et al. 2005) and UNEP (UNISDR 2009) that assess current exposure to all natural disasters, including climate-related disasters of cyclones, droughts, floods, wildfires and landslides. These are not climate change hotspots per se, since they do not assess future scenarios, but the data layers have been used in a number of climate change hotspots efforts.

One such effort was by CARE and Maplecroft (2008; Thow and de Blois 2008), which sought to identify the most likely humanitarian implications of climate change for the next 20-30 year period. The authors use the World Bank hazard hotspots - floods, cyclones and droughts - to map specific hazards associated with climate change in relation to factors influencing vulnerability. Beyond the climate hazards, two climate projections were used: percentage change in maximum dry periods under scenario A1B and future dynamics of drought risk from 2041-2070. To map sensitivity to climate impacts, the authors combined indicators to create separate indices of natural vulnerability (poor natural resource base), human vulnerability, social vulnerability, financial vulnerability, and physical vulnerability (infrastructure). These layers were then combined into an overall human vulnerability index (Figure 8). Hotspots include the Andes, the landlocked countries of sub-Saharan Africa as well as southern Mozambique and Namibia, Yemen, Afghanistan and Pakistan, Mongolia, and Myanmar. One weakness is 
Revised Accepted Manuscript submitted to Climatic Change (8 August 2013).

that the authors do not combine the climate risks (past hazards and future scenarios) with the human vulnerability index in such a way as to draw out hotspots at the intersection of climate and societal vulnerability.

\subsection{Agriculture and food security hotspots}

There are a number of recent reports looking at climate change and food security hotspots. Under the Climate Change, Agriculture and Food Security (CCAFS) program, Ericksen et al. (2011) map hotspots of climate change and food insecurity in the global tropics using a series of spatial indicators for climate change and food security. Indicators for climate change were based on model runs from three models obtained through the Coupled Model Intercomparison Project (CMIP3), and featured factors such as reductions in length of growing season, areas where average annual maximum temperatures will exceed $30^{\circ} \mathrm{C}$ (an important threshold for legumes), and areas where the rainfall coefficient of variation is $>20 \%$. These were tallied into an index identifying the number of climate change thresholds important to agriculture that are likely to be exceeded. Indicators for food security include food availability (current crop yields and a food production index), access (GDP per capita, percent population living on less than $\$ 2 /$ day, road density), utilization (stunting prevalence, wasting prevalence, malnourished children per sq. $\mathrm{km}$, population using unimproved water sources), and resource pressure (population growth rate, arable land p.c.).

In a last step, the results are tallied by exposure, sensitivity and coping capacity components into eight vulnerability domains, from high-high-high to low-low-low. Although sophisticated, the resulting array of maps is challenging to interpret without specialized knowledge, and little attempt is made to highlight hotspot scenarios of greater concern or likelihood. Adding to the problems of interpretation, maps represent eight vulnerability dimensions in various shades of yellow, green, blue and red. Focusing on domains with high exposure, high sensitivity, and low coping capacity, which are helpfully mapped in red, hotspots include the forest belt of West Africa, northwestern India and northeastern Pakistan, and in the lower Mekong that are highly affected by changes in growing season length. Areas of Nigeria, the lakes region of Africa, and large swaths of India will be affected by a change in average maximum daily growing season temperatures of $>30^{\circ} \mathrm{C}$ (Figure 9). Southern Nigeria and parts of the Gangetic plain will be severely affected by rainy season rainy day decreases of $>-10 \%$.

Fraser et al. (2012) map drought vulnerability hotspots with reference to wheat and maize. Unlike the CCAFS maps, which portray seemingly small impacts, by circa 2050 broad swaths of the world are deemed vulnerable to declines of growing season soil moisture availability of greater than $25 \%$, including most of South America, the U.S. mid-West, Southern Africa, the Mediterranean Basin, Central Asia, western China, and Australia. When combined with reduced adaptive capacity, there are five wheat and three maize vulnerability hotspots. For wheat, these are the southeastern U.S., southeastern South America, the northeastern Mediterranean, and parts of central Asia, and for maize they are southeastern South America, parts of southern Africa, and the northeastern Mediterranean (Figure 10).

Kok et al. (2010) use an integrated assessment framework to assess livelihood security as a consequence of global change, assessing four patterns of vulnerability: smallholder farming in dryland areas, overexploitation of natural resources, competition for land for food and biofuels, and rapid urbanization in the coast fringe (Figure 11). Similar to Ericksen et al., the range of factors considered (resource rich; resource poor; poor water, better soils; developed) makes interpretation difficult, but 
there are swaths or resource poor areas with severe to moderate poverty that are more vulnerable to global change, including the Sahel, the Horn of Africa, Afghanistan, and small areas of western China. The Andes, southern Maghreb, Arabian peninsula, Iran and Pakistan and the rest of western China are deemed to be resource poor with only moderate poverty.

\subsection{Water resources hotspots}

There is a growing effort to map climate and water hotspots. Parish et al. (2012) sought to integrate climate and population data sources to develop first order per capita water availability projections at the global scale. Like many analyses, the authors sought to determine if there may be any new hotspots of water scarcity under a changing climate regime that would require planning and mitigation. Beyond identifying hotspots, the authors were interested in identifying the relative contributions of population and climate change as drivers of water availability. The study used climate projections and multiple SRES scenarios ( $A 1 B, B 1, A 2$, and $A 1 F 1$ ) as inputs to a hydrological model. To assess population growth, they apply SRES country-level population projections to the Landscan population grid, assuming a constant relative distribution of population within countries. The map depicting the A1F1 SRES scenario (high emissions) (Figure 12, bottom right) depicts quite disparate areas at high risk - ranging from the region surrounding the Great Lakes in the U.S. and Canada, to North Africa, to Iraq and Syria to Southern Russia. Some areas where one might expect increases in stress, e.g., China and India, are actually depicted as showing declining water stress across most scenarios (except in the A2 scenario) owing to projected increases in precipitation. The patterns are not very consistent across SRES scenarios, and there are many isolated "hotspot" pixels, making interpretation difficult.

Similar assessments have been conducted by Döll (2009) for climate change and population impacts on groundwater resources, focusing on ground water recharge rates, and De Stefano et al. (2010) for international river basins to future climate change-induced water variability. Döll finds more consistent evidence across the GCMs utilized, with patterns of high vulnerability to decreases in groundwater resource availability in North Africa, Senegal and Mauritania, Namibia and western South Africa, and northeastern Brazil. De Stefano finds high projected water runoff variability by 2030 for the Colorado Basin in the U.S. Southwest, the Parana in South America, basins in West Africa and southern Africa, the Mekong, and southern China.

\section{Discussion and Conclusions}

This paper reviewed a range of global and regional (in the SOM) hotspots mapping efforts. While hotspots maps are issued with increasing regularity, there are a number of fundamental issues that need to be addressed. In this section I briefly assess data and methodologies, identify regions that are consistently identified as hotspots, address communication and design issues, discuss hotspots maps as tools for decision making, and identify paths for future research.

\subsection{Data and methodologies}

There are a number of common conceptual and methodological approaches that are found across multiple mapping efforts. One is the frequent use of the IPCC conceptualization of vulnerability, which either directly or indirectly served as the basis for six of the efforts reviewed, although not all adequately addressed the three components. As already discussed, there remain challenges in data 
availability and mapping scales for a number of socioeconomic variables relevant to the mapping of sensitivity and adaptive/coping capacity. Often, proxies such as poverty and malnutrition are used to measure social vulnerability, yet it is acknowledged in the literature that this is a multidimensional, time dependent and often complex concept that is difficult to capture in static maps (Kasperson et al. 2005). More fundamentally, the SREX framework (IPCC 2012) - which separates exposure and vulnerability may yield better results for policy audiences since it translates more easily into a risk management approach.

Climate projections tend to be more common in hotspots studies of biophysical systems, especially as inputs to other models, and are rarely used for social or "general" vulnerability assessments (exceptions include Midgley et al. 2011, CARE and Maplecroft 2008). Apart from Busby et al. (2011), climate and security mapping efforts appear to be less sophisticated, relying to a greater extent on expert opinion (e.g., Schubert et al. 2007). Overall, there are strong disciplinary influences reflected in each of the approaches. The $\mathrm{RCCl}$ and $\mathrm{CCl}$ are entirely grounded in climate science, the CVI in ecology, the livelihood systems mapping in integrated assessment (Kok et al. 2010) and development practice (Warner et al. 2009, Thornton et al. 2008), and most agriculture and water hotspots maps are generated by modelers.

Many hotspots mapping efforts are affected by the spatial scale and uncertainties in the available global data sets. Kok et al. point out that there is a gap between local vulnerability assessment, which address context-specific situations with more detailed data, and the kinds of analyses possible for global VAs, which are based on aggregated data and rather crude assumptions about the underlying mechanisms being assessed. Bridging this gap will prove to be difficult.

\subsection{Where are the hotspots?}

Based on the figures and Table 2 found in the SOM, there are a number of regions that are found to be vulnerable across a range of climate impacts and systems, sectors, and groups. These include North Africa, the Sahel, the Horn of Africa, parts of southern Africa, Central America, and the Andes. In Asia, the picture is less consistent, but western China and Central Asia are fairly consistently identified, and often India as well. Parts of Europe, North America and South Asia are also found to be vulnerable to agricultural production declines. Many small islands states, particularly in Oceania and the Caribbean, are highly vulnerable to SLR and storm surge, but these islands rarely show up in global mapping efforts because they are too small to map adequately at global scales. A number of the data-driven GIS modeling efforts produce patterns that are not always intuitive, and the number of map outputs makes summarizing overall patterns difficult.

One obvious question is, Do the data-driven maps show patterns that would not have been identified in an expert assessment approach or based on a broad understanding of past patterns? This depends on the mapping efforts, but for the most part it appears that regions that have the lowest levels of economic development are typically found to be most at risk in global hotspots mapping assessments, which suggests that patterns are not radically different from what one might expect $a$ priori. Indeed, many hotspots were already identified as having high vulnerabilities by the IPCC (Parry et al. 2007). However, the specific sub-regions identified vary from effort to effort, and the climate change exposure and SLR hotspots do include areas that are economically advanced because they are climatedriven. 


\subsection{Design and communication of results}

Maps are fundamentally a communication tool, answering the question, Where should I focus my attention? Maps have been proven particularly effective in risk communication (Dransch et al. 2010). Yet, some maps reviewed in this article are more effective than others in drawing attention to specific locations. For data driven maps, the "speckling" that results from isolated pixels showing up as hotspots is problematic from a policy communications perspective. A majority filter (moving window or spatial averaging) could reduce the speckling at the risk of some information loss (compare Figures 15a and 15b), and better convey uncertainties. The abrupt discontinuities across borders create problems for interpretation: they may be an artifact of using national level vulnerability and resilience indicators, or they may reflect real changes in on-the-ground vulnerability based on differing governance structures.

Reports by Busby et al. (2012), Warner et al. (2009 and 2012), and Midgley et al. (2011) are professionally designed, and the maps are cartographically appealing. Busby provides map zooms for specific sub regions, which aids greatly in legibility (Figure 14). However, for most maps, their frequently small size and lack of contextual information (subnational boundaries, road networks, major cities) makes it difficult to identify the locations of hotspots. Some important areas such as small island states or major urban areas, where vulnerabilities are likely to be greatest, are often completely obscured on global scale maps. Maps zoomed to areas of vulnerability with greater contextual information could be used to address these concerns.

Researchers coming from the climate and integrated assessment communities tend to produce map arrays depicting multiple scenarios. This reduces legibility and can lead to confusion in the reader's mind since there is seldom any guidance on how to interpret the range of scenarios, or whether under certain assumptions one outcome is more likely than another. Thus, on the one hand, the range of scenarios highlights uncertainties, which is important for risk management, and on the other, the lack of guidance can result in information overload. As Patt and Dessai (2005:427) point out, users have varying abilities to understand probabilistic information, and "people will either choose to ignore information that is too complicated for them, or will respond in ways that disproportionately makes use of some types of information over others." One approach commonly employed by the climate research community is to provide cross hatching of various densities on maps representing climate ensemble outputs, which indicates the percentage of scenarios that agree on the direction of change.

A broader issue is that the proliferation of hotspots mapping risks overloading decision makers with either too much or conflicting information (see Figure 16). Furthermore, where identified hotspots do not conform to decision makers' mental models, it is an open question as to whether decision makers will accept results. This brings us to the topic of maps as tools for decision making.

\subsection{Hotspots maps as tools for decision making}

One common assumption is that hotspots maps hold out the potential for more "transparent" and data driven decision making with regards to adaptation funding allocations, much as indicators are presumed to distill complex information in ways that are useful to decision making (Abson et al. 2012). A common assertion by map authors is that their results will be useful to policy audiences.

Yet hotspots efforts tend to be plagued by a lack of specificity regarding who precisely constitutes the "policy audience". While aid agency clients may indeed use the maps to identify priority areas for 
investments (see Table 2 for funders), it seems unlikely that national or local policy makers will take up the maps as planning tools. Many country level decision makers distrust global/regional mapping efforts because they don't understand/accept the methods, or question data inputs if they are not from their own national agencies. There is little direct evidence that the maps actually influence investments or adaptation activities, but Preston et al. (2011) suggest that maps may serve as boundary objects that facilitate discourse.

More broadly, there is a risk, should the maps actually influence decisions, that quantification gives decision-makers the false impression that the information is more "objective" (Preston et al. 2011). Yet the framing of issues and selection of indicators cannot be presented as purely the result of objective scientific criteria. By reifying vulnerability and resilience, and relying on proxies, other qualitative aspects such as culture, power relations, and local ecological knowledge can be overlooked or downplayed (Adger 2006; Kasperson et al. 2005). Seemingly innocent and value neutral, maps could play an important role in framing societal responses to climate change and its impacts in ways that are surely not neutral.

With increased attention and funding being devoted to adaptation, there is now a financial incentive for countries to portray themselves as highly vulnerable to climate impacts. Yet, should donors use hotspots maps to guide investments, there is a potential to reward countries with poor governance should they be identified as the most vulnerable. Conversely, there is a moral hazard that countries could suffer funding "triage" if they are deemed overly vulnerable to climate impacts. The role of hotspots maps in political discourse and guiding decisionmaking deserves more attention.

\subsection{Suggestions for future research}

Some have suggested an alternative "hot systems" approach, which consider perturbations to socio-economic and ecological systems in disparate geographic locations (Shen et al. 2010). Similar to "syndromes" (Lüdeke et al. 2004), this approach would identify system characteristics across locations as well as teleconnections owing to "expanding markets and flows of resources, people, information and power relations", with a focus on "particular combinations of events and conditions in geographically disparate systems [that] can lead to ... crises" (p.15). While more complex than simply mapping local processes, there is no fundamental reason why the results of such "hot systems" approaches cannot be mapped. For example, Lüdeke et al. map global change syndromes in much the same way that hotspots have been mapped (Figure 13). This would add sophistication to current efforts by better reflecting direct and indirect drivers of change and real-world teleconnections.

There are a number of other potentially fruitful areas for further research. A useful next step in this research would be to take spatial outputs of essentially similar hotspots mapping efforts, and overlay them to see if results are broadly similar (Figure 16). Another area for further research would be to interview decision makers at aid agencies in government agencies concerning the impact that the maps had on resource allocation decisions. Finally, it would be interesting to use eye-tracking software and other cognitive research tools being applied in the field of data visualization to understand how the human brain processes the information contained on the maps with a goal of improving their communication efficacy (Montello and Freundschuh 2005). 


\section{Conclusion}

This paper reviews a number of global and regional hotspots mapping efforts, assessing data and methods, the hotspots identified, and their efficacy as tools for risk communication and decisionmaking. Efforts to date can largely be characterized as supply-driven academic exercises rather than responding to demands from the policy community. Yet in a world where human security is potentially imperiled by temperature increases of $>4^{\circ} \mathrm{C}$, and where "loss and damage" has become part of the UN Framework Convention on Climate Change lexicon, demand for hotspots maps will likely increase as decisionmakers seek to identify where impacts will be greatest and what adaptation measures, if any, are possible.

\section{Acknowledgements}

The author would like to acknowledge comments on an earlier version of this paper by Richard Sliuzas of ITC/University of Twente and by three anonymous reviewers. The author also presented earlier versions of this paper and benefited from exchanges with researchers at the ICARUS II and Adaptation Futures conferences in May 2012.

\section{References}

Abson, D. J., A. J. Dougill, and L. C. Stringer. 2012. Using Principal Component Analysis for informationrich socio-ecological vulnerability mapping in Southern Africa. Applied Geography, 35, 515-524.

Adger, N. 2006. Vulnerability. Global Environmental Change, 16: 268-281.

Baettig, M.B., M. Wild, and D.M. Imboden. 2007. A climate change index. Geophysical Research Letters, 34, L01705

Barnett, J., S. Lambert, and I. Fry (2008). "The hazards of indicators: insights from the Environmental Vulnerability Index." Annals of the Association of American Geographers 98(1): 102-119.

Birkmann, J., D. Krause, N. Stiadi, D. Suarez, T. Welle, J. Wolfertz. 2011. World Risk Report. Bonn, Germany: UNU and IEHS.

Birkmann, J., and B. Wisner. 2006. Measuring the Un-Measurable. UNU-EHS SOURCE No. 5, Bonn, Germany: UNU-EHS.

Black, R., S.R.G. Bennett, S.M. Thomas, and J.R. Beddington. 2011. Migration as Adaptation. Nature 478: 447-449.

Brown, C. and R. L. Wilby. 2012. An Alternate Approach to Assessing Climate Risks. Eos, 93(41): 401402.

Busby, J.W., T.G. Smith, and K.L. White. 2011. Locating Climate Insecurity: Where are the most vulnerable places in Africa? Climate Change and African Political Stability Program Policy Brief No.

3.

CARE and Maplecroft. 2008. Humanitarian implications of climate change: Mapping emerging trends and risk hotspots. Geneva, Switzerland: CARE International. 
Revised Accepted Manuscript submitted to Climatic Change (8 August 2013).

Davies, R.A.G., and S.J.E. Midgley. 2010. Risk and Vulnerability Mapping in Southern Africa: A Hotspots Analysis. Cape Town, South Africa: OneWorld Sustainable Investments (Pty) Ltd.

de Sherbinin, A., K. Warner, and C. Ehrhart. 2011. Casualties of Climate Change, Scientific American, January 2011: 64-71.

De Stefano, L., J. Duncan, S. Dinar, K. Stahl, K. Strzepek, and A.T. Wolf. 2010. Mapping the Resilience of International River Basins to Future Climate Change-Induced Water Variability. Water Sector Board Discussion Paper Series No. 15. Washington DC: The World Bank.

Diffenbaugh, N. S., F. Giorgi, and J. S. Pal. 2008. Climate change hotspots in the United States, Geophysical Research Letters, 35, L16709.

Dilley, M., R. Chen, U. Deichmann, A. Lerner-Lam, and M. Arnold. 2005. Natural Disaster Hotspots. Washington, DC: World. Bank.

Döll, P. 2009. Vulnerability to the impact of climate change on renewable groundwater resources. Environmental Research Letters, 4:035006. doi:10.1088/1748-9326/4/3/035006

Dransch, D., H. Rotzoll, and K. Poser. 2010. The contribution of maps to the challenges of risk communication to the public. Intl Journal of Digital Earth, 3(3):292-311.

Eakin, H., and A. Luers. 2006. Assessing the vulnerability of socio-environmental systems. Annual Review of Environment and Resources. 31:365-94.

Ericksen, P., P. Thornton, A. Notenbaert, L. Cramer, P. Jones, M. Herrero. 2011. Mapping hotspots of climate change and food insecurity in the global tropics. CCAFS Report no. 5. Copenhagen, Denmark.

ESPON Climate. 2011. Climate Change and Territorial Effects on Regions and Local Economies. Applied Research 2013/1/4. Final Report, Version 31/5/2011.

Fraser, E.D.G., E. Simelton, M. Termansen, S.N. Gosling, and A. South. 2013. "Vulnerability hotspots": Integrating socio-economic and hydrological models to identify where cereal production may decline in the future due to climate change induced drought. Agricultural and Forest Meteorology, 170: 195-205.

Füssel, H.-M. 2007. Vulnerability: A generally applicable conceptual framework for climate change research. Global Environmental Change, 17:155-167.

Giorgi, F. 2006. Climate change hot-spots, Geophysical Research Letters, 33, L08707, doi:10.1029/2006GL025734.

Hagenlocher, M., S. Lang, D. Holbling, et al. 2013. Modeling Hotspots of Climate Change in the Sahel Using Object-Based Regionalization of Multidimensional Gridded Datasets. IEEE Journal of Selected Topics in Applied Earth Observations and Remote Sensing. doi: 10.1109/JSTARS.2013.2259579

IPCC (Intergovernmental Panel on Climate Change). 2012. Managing the Risks of Extreme Events and Disasters to Advance Climate Change Adaptation. Field, C.B., et al. (eds.). Cambridge University Press, Cambridge, UK, and New York, NY, USA, 582 pp.

Kasperson R.E., K. Dow, E. Archer, D. Caceres, T. Downing, et. al. 2005. Vulnerable People and Places. Chapter 6 in: Millennium Ecosystem Assessment. Washington, DC: Island Press.

Kok, M.T.J., M.K.B. Lüdeke, T. Sterzel, P.L. Lucas, C. Walter, P. Janssen and I. de Soysa. 2010. Quantitative analysis of patterns of vulnerability to global environmental change. Den Haag/Bilthoven, Netherlands: PBL. 
Revised Accepted Manuscript submitted to Climatic Change (8 August 2013).

Liu, J., S. Fritz, C.F.A. van Wesenbeeck, M. Fuchs, L. You, M. Obersteiner, H. Yang. 2008. A spatially explicit assessment of current and future hotspots of hunger in Sub-Saharan Africa in the context of global change. Global and Planetary Change, 64 (2008): 222-235.

Lüdeke, M.K.B., G. Petschel-Held, H.J. Schellnhuber. 2004. Syndromes of Global Change. GAIA Ecological Perspectives for Science and Society, 13(1):42-49.

McGranahan, G., D. Balk, and B. Anderson. 2007. Low Elevation Coastal Zone (LECZ) Urban-Rural Population Estimates. Palisades, NY: NASA SEDAC.

Midgley, S.J.E., R.A.G. Davies, and S. Chesterman. 2011. Climate Risk and Vulnerability Mapping: Status quo (2008) and future (2050). Report produced for UK Department for International Development (DFID).

Montello, D.R., and S. Freundschuh. 2005. "Cognition of Geographic Information". In: R.B. Mc.Master and E.L. Usery (eds.), A Research Agenda for Geographic Information Science. Boca Raton FL: CRC Press.

Myers, N. 1990. Threatened Biotas: Expanded Hot-Spots Analysis, The Environmentalist 10:243-256.

O'Brien, K.L., S. Eriksen, L. Nygaard, and A. Schjolden. 2007. Why Different Interpretations of Vulnerability Matter in Climate Change Discourses. Climate Policy 7: 73-88

Parry, M.L., O.F. Canziani, J.P. Palutikof, P.J. van der Linden and C.E. Hanson (eds). 2007. Climate Change 2007: Impacts, Adaptation and Vulnerability. Cambridge, UK: Cambridge University Press.

Parish, E.S., E. Kodra, K. Steinhauser, and A.R. Ganguly. 2012. Estimating future global per capita water availability based on changes in climate and population. Computers \& Geosciences, 42: 79-86.

Patt, A., and S. Dessai. 2005. Communicating uncertainty: lessons learned and suggestions for climate change assessment. C.R. Geoscience, 337:425-441.

Piontek, F., C. Müller, T.A.M. Pugh, et al. 2013. Multisectoral climate impacts in a warming world. Proceedings of the National Academy of Sciences (early online edition), doi:10.1073/pnas.1222471110.

Preston, B., E.J. Yuen, R.M. Westaway. 2011. Putting vulnerability to climate change on the map: a review of approaches, benefits, and risks. Sustainability Science, 6:177-202.

Samson, J., D. Berteaux, B.J. McGill and M.M. Humphries. 2011. Geographic disparities and moral hazards in the predicted impacts of climate change on human populations. Global Ecology and Biogeography doi:10.1111/j.1466-8238.2010.00632.x

Scheffran, J., and A. Battaglini. 2011. Climate and conflicts: the security risks of global warming. Regional Environmental Change 11(Suppl 1):S27-S39. doi:10.1007/s10113-010-0175-8

Schröter, D., W. Cramer, R. Leemans, et al.. 2005. Ecosystem Service Supply and Vulnerability to Global Change in Europe. Science 310:1333-1337.

Schubert, R., H.J. Schellnhuber, N. Buchmann, A. Epiney, R. Grießhammer, M. Kulessa, D. Messner, S. Rahmstorf, and J. Schmid. 2007. Climate Change as a Security Risk. London: Earthscan and German Advisory Council on Global Change (WBGU).

Shen, X., T.E. Downing and M. Hamza (eds). 2010. Tipping Points in Humanitarian Crisis: From Hot Spots to Hot Systems. Studies of the University: Research, Counsel, Education (SOURCE) Publication Series of UNU-EHS, No. 13/2010. 
Thornton, PK, PG Jones, T Owiyo, RL Kruska, M Herrero, V Orindi, S Bhadwal, P Kristjanson, A Notenbaert, N Bekele and A Omolo. 2008. Climate change and poverty in Africa: Mapping hotspots of vulnerability. AfJARE 2 2(1) March 2008.

Thow, A., and M. de Blois. 2008. Climate change and human vulnerability: Mapping emerging trends and risk hotspots for humanitarian actors. Geneva: Maplecroft, and CARE International.

Torres, R.R., D.M. Lapola, J.A. Marengo, M.A. Lombardo. 2012. Socio-climatic hotspots in Brazil. Climatic Change, 115:597-609.

UNISDR. 2009. Global Assessment Report on Disaster Risk Reduction. Geneva: United Nations.

Warner, K., T. Afifi, K. Henry, T. Rawe, C. Smith, and A. de Sherbinin. 2012. Where the Rain Falls. Bonn, Germany: UNU and CARE.

Warner, K., C. Erhart, A. de Sherbinin, S.B. Adamo, T.Chai-Onn. 2009. In Search of Shelter. Bonn, Germany: UNU.

Yohe, G., E. Malone, A. Brenkert, M. Schlesinger, H. Meij, X. Xing, and D. Lee. 2006. Global Distributions of Vulnerability to Climate Change. The Integrated Assessment Journal, 6(3): 35-44.

Yusuf, A.A., and H. Francisco. 2009. Climate Change Vulnerability Mapping for Southeast Asia. Singapore: EEPSEA. 


\section{Supplementary Online Material - Climate Change Hotspots Mapping}

\section{SOM 1. Regional hotspots mapping efforts}

In this section I review a number of regional GIS-based hotspots mapping efforts from Africa, Southeast Asia, and Europe.

\section{SOM 1.1. Hotspots Maps for Africa}

Owing to chronically low levels of development, high levels of food insecurity and natural resource dependence, and high climate variability, many studies find that Africa is likely to be the continent hardest hit by climate change (e.g. Thornton et al. 2008, Parry et al. 2007, Yohe et al. 2006). Busby et al. (2011) develop a map of potential climate conflict hotspots based on a geospatial overlay technique that is similar to the humanitarian mapping described above. A composite vulnerability score includes four components: exposure to climate hazards, population density, household and community resilience (health, education, access to health care), and governance and political violence (country level indicators of government responsiveness, effectiveness, polity, and violence against civilians). A useful feature of this report is the focus on specific regions as case examples, where the index is deconstructed (Figure 14). Overall, regions that are identified as having the highest vulnerability include much of the Democratic Republic of Congo, Sierra Leone, Somalia, Sudan, Chad and Ethiopia. Portions of Angola, Niger, Cote d'Ivoire, and Central African Republic are also considered vulnerable. Although the maps are attractive, given their histories of conflict there is little surprise that these regions emerge as vulnerable.

Two studies have developed human vulnerability hotspots maps for southern Africa, which is one of the sub-regions of Africa that has been pin-pointed as being particularly vulnerable to climate change (Parry et al. 2007). In the first, Midgley et al. (2011) focus is on agriculture, food security, and human health in southern Africa (see also Davies and Midgley 2010). The authors use an index approach with spatial data sets that measure present exposure, future exposure (in 2050), sensitivity and adaptive capacity. Present exposure variables include, inter alia, the rainfall coefficient of variation, risk of cyclones and floods, the standardized precipitation index, fire frequency, and disaster events. Future exposure includes future population density, ensemble GCM outputs for precipitation and temperature change, loss of suitability for crop land, and sea level rise. Sensitivity includes variables such as irrigated land, volume of rainfall per person on agricultural land, crowding on agricultural land, length of growing season, soil degradation, slope, and net primary productivity. Adaptive capacity includes variables such as infrastructure, economic wealth, malnourishment, education, health, malaria, access to improved water, travel time to cities, and night time lights.

All variables were standardized on a $0-1$ scale and then multiplied times a weight ranging from 1 to 3 , and then all variables were added to form a score for each component of vulnerability (Figure 15). Most of the adaptive capacity indicators, and those with the greatest weight such as GDP and access to water and sanitation, tend to be reported at national levels, so there are abrupt jumps in values at national borders. Sensitivity tends to be heavily influenced by population density, which is not directly incorporated but is implicitly present through measures such as human appropriation of net primary productivity and per capita volume of rainfall. 
In the second vulnerability hotspots mapping effort for southern Africa, Abson et al. (2012) created vulnerability maps based on principal components analysis (PCA). They argue that the standard practice of averaging or summing indicator scores hides important information regarding the relations between the original variables. Because the principal components (PCS) are uncorrelated, the scores associated with each PC encapsulate a unique aspect of the overall socio-ecological vulnerability represented by the original set of vulnerability indicators. However, since the components are statistically derived, it can be difficult to attribute meaning to a specific component. For example, their first PC, which they term "poverty and health vulnerability", includes infant mortality, poverty, agricultural constraints, and malnutrition, which is straightforward enough. But their third PC, termed "infrastructure poverty and population pressure vulnerability", combines population per net primary productivity, infrastructure poverty (a measure of population divided by night time lights), and travel time to major cities. It is hard to make sense of this except perhaps as a proxy for population density.

Figure 16 provides a comparison of the results by these two efforts, revealing broadly similar patterns but also some notable differences. For example, Midgley et al. find Zimbabwe and southern Zambia to be highly vulnerable but Abson et al. find them to be less so. Conversely, Abson et al. find most of the Congo and Angola to be highly vulnerable, but Midgley et al. find them to be less so. While the results are not directly comparable owing to the use of different indicator sets, it does serve to illustrate the fact that depictions of vulnerability patterns in spatial index approaches depend heavily on data and methods.

Liu et al. (2008) focus on hunger hotspots using multiple crop modeling outputs. They identify areas of high population density and current undernutrtion problems that are likely to see decreases in per capita calorie availability of $0-30 \%$ and $>30 \%$ (Figure 17). A major area of current and future vulnerability is the highlands of Ethiopia; Areas stretching from western Tanzania to Mozambique are projected to see $>30 \%$ declines in calorie intake, and the lakes region, northern Nigeria, and parts of southern Nigeria are considered currently vulnerable but without significant changes in future calorie intake.

Thornton et al. (2008) map hotspots of climate change and poverty in Africa using principle components analysis on 14 indicators measuring five livelihood capitals (Carney 1998): natural capital (e.g. soil degradation), physical capital (e.g., accessibility to markets), social capital (e.g., governance), human capital (e.g., malaria and HIV prevalence), and financial capital (e.g., agricultural GDP). Regions identified as most vulnerable include the Highlands of Ethiopia, southern Chad, southern Niger, and Rwanda and Burundi, followed by most of the rest of Africa, with only Guinea, southern Ghana, Namibia, and Zimbabwe and portions of South Africa near Johannesburg showing up as less vulnerable. The selection of Guinea and Zimbabwe as less vulnerable is puzzling, and may have to do with data limitations.

Finally, Hagenlocher et al. (2013), in a climate-focused approach similar to that of Baettig et al.'s $\mathrm{CCl}$, develop an innovative modeling approach using historical climatological and vegetation index data sets to delineate areas with relatively high climate change impacts in West Africa. Hotspots are identified as areas where temperature and precipitation trends are pronounced and drought and flood events over the past 24-36 years have been severe, with a focus on the rainy season from May to October. The map (Figure 18) reveals both the areas of high impacts, and the proportion of the impact that can be attributable to given impacts. For example, flood impacts dominate in the hotspots of 
Revised Accepted Manuscript submitted to Climatic Change (8 August 2013).

Burkina Faso, Ghana, and southern Niger, whereas precipitation trends dominate in western Mauritania. The maps lack any reference to population vulnerability, but some hotspots do coincide with larger population centers, such as the flood hotspots in northern Nigeria (around Kano) and in southern Burkina Faso. The approach also does not differentiate between increasing and decreasing trends in precipitation, such that the rebound in precipitation following the great Sahelian droughts of the early 1970 s and 1980s would be considered as contributing to climate hotspots in some regions.

\section{SOM 1.2. Hotspots Map for Southeast Asia}

In a similar effort, Yusuf and Francisco (2009) sought to map vulnerability to climate change in Southeast Asia. They developed a vulnerability index following the IPCC definition, including natural hazards, population density as a proxy for human sensitivity, protected areas as a proxy for ecological sensitivity, and a number of variables for adaptive capacity. They did not incorporate GCM outputs or socioeconomic scenarios. The resulting vulnerability map (Figure 19) depicts areas of particularly high vulnerability in Laos, Cambodia, the Philippines, and the regions of Java and West Papua (former Irian Jaya) in Indonesia. The results appear to be largely driven by the Climate Hazard Index for all regions except Laos and Cambodia, where adaptive capacity is very low.

\section{SOM 1.3. Hotspots Maps for Europe}

The ESPON Climate (2011) mapping effort mapped potential impacts of climate change on Europe at the Nomenclature of Territorial Units for Statistics (NUTS) 3 level, which are approximately equivalent to US counties. The authors looked at physical impacts, such impacts on settlements, roads, railroads, airports, power plants, and harbors, as well as social impacts on populations, using proxies such as age and population density. Figure 19 depicts the map of potential vulnerability to climate change, which combines regional potential impacts with regional adaptive capacity. Impacts are calculated as exposure based on the difference between 1971-2000 and 2071-2100 based on eight climatic variables of the CCLM model for the SRES A1B scenario, plus inundation depth changes for a 100 year return flood event, change in 100 year return period coastal storm surge height, together with recent data on the physical, economic, social, environmental and cultural sensitivity to climate change. Adaptive capacity was calculated as a weighted combination of economic, infrastructural, technological and institutional capacity as well as knowledge and awareness of climate change.

The results suggest high levels of vulnerability in much of southern Europe and medium vulnerability in selected coastal regions of France, Netherlands, and the UK. Some of these patterns are driven by increasing flood and surge risk along the coasts, but the broad pattern of vulnerability in southern Europe is driven most by projected hotter and drier climates combined with low adaptive capacity.

Schröter et al. (2005) focus on the vulnerability of ecosystem services to climate change impacts in Europe using multiple SRES scenarios out to the year 2080. They find that some changes reduce vulnerability, e.g., through the increase in growing days and more favorable agricultural conditions in northern latitudes, but most changes increase vulnerability, e.g., through declining soil fertility, declining water availability, and increasing risk of forest fires, especially in the Mediterranean and mountain regions. Their maps do not represent overall hotspots, but rather present information on changes to 
Revised Accepted Manuscript submitted to Climatic Change (8 August 2013).

specific ecosystem services, such as changes to cropland areas and water stress. Here again, southern Europe appears to be most impacted across multiple scenarios.

\section{SOM 2. Hotspots mapping based on expert opinion}

In this section I review a number of hotspots maps based on expert judgment, which use maps or spatial data to illustrate climate change impacts or to "tell a story".

\section{SOM 2.1. Population dynamics and migration hotspots}

Warner et al. (2009 and 2012) represent a hybrid of expert judgment in the selection of hotspots and combinations of spatially explicit data for mapping. The maps in the report In Search of Shelter (Warner et al. 2009) highlight how climate impacts may adversely impact livelihoods, which in turn could precipitate human migration. They focus on several locations deemed to have high livelihood vulnerability and therefore susceptibility to increased migration, such as the semi-arid agricultural systems of Mexico/Central America (Figure 20). The maps in the report Where the Rainfalls (Warner et al. 2012) complement field research in eight countries on rainfall variability and migration as a coping mechanism. The strength of these efforts is in their tailoring of representations of vulnerability to the specific regions of interest, acknowledging that the major issues facing each region will be different, and the use of well designed maps to draw policymaker and media attention. A weakness is that it is not a systematic or quantitative assessment, and the regions identified as hotspots may not be the most important based on objective criteria.

In 2005 UNEP published a map depicting areas where climate impacts are likely to drive climate migration under the heading " 50 million climate refugees by 2010 " (Figure 21). The map generated some controversy when The Wall Street Journal pointed out that many areas predicted to be major sources of "climate refugees", such as coastlines, by 2010 were in fact areas of in-migration. ${ }^{1}$ Because they are based on expert judgment, such maps may be risky since they are assumed to be fabrications by climate skeptics.

\section{SOM 2.2. Security and conflict hotspots}

Expert judgment and "freehand" mapping has been widely used in climate security studies. For example, a report by Shubert et al. (2007) for the German Advisory Council on Global Change (WBGU) uses icons to identify regions at risk of water insecurity, declining food production, climate change increase in storm and flood disasters, and environment (Figure 23). The hotspots are schematically represented and provide a broad-brush, subjective assessment. According to the authors, the map "takes account of the social, political and economic conditions that determine the emergence of a conflict constellation in a given region; [it] summarizes the security risks arising from climate change for a set of regions selected as examples" (p.162).

Similarly, Scheffran and Battaglini (2011) identify climatic stressors that could result in conflict using a global map drawn in freehand to identify broad regions where climate change could result in security

1 “Climate Refugees, Not Found: Discredited by reality, the U.N.'s prophecies go missing." Wall Street Journal, 21 April 2011. 
risks (Figure 24). Examples include droughts and general water scarcity (e.g., in the Mediterranean basin and western and central Asia), recurrent flooding (e.g., in coastal East Asia and parts of the Caribbean), loss of ecosystems and ecosystem services (e.g., across the arctic), extreme events (e.g., in Central America and Indonesia), and loss of coastal areas owing to SLR (e.g. in Oceania). Apart from illegibility and poor cartography, the map fulfills the purpose of distilling major issues. A weakness of both mapping efforts is the lack of underlying data and over-reliance on the authors' subjective assessments. 


\section{Annex: Tables and Figures}

Table 1. Hotspots mapping efforts reviewed for this paper

\begin{tabular}{|c|c|c|c|c|}
\hline Reference & System & Valued Attribute & External Hazard & Temporal Reference \\
\hline \multicolumn{5}{|c|}{ Global Hotspots Mapping Efforts (data driven) } \\
\hline Giorgi (2006) & .. & $\begin{array}{l}\text { Implicit: Climate } \\
\text { stability }\end{array}$ & Climate variability & $\begin{array}{l}2080-2099 \text { against a } \\
\text { baseline of } 1960-79\end{array}$ \\
\hline Baettig et al. (2007) & .. & $\begin{array}{l}\text { No chg in probability } \\
\text { distrib. of extremes }\end{array}$ & $\begin{array}{l}\text { Increased probability of } \\
\text { hot/wet/dry years }\end{array}$ & $\begin{array}{l}\text { 2071-2100 against a } \\
\text { baseline of } 1961-90\end{array}$ \\
\hline UK Met Office (2009) & Multiple & Multiple & Temperature change & $\begin{array}{l}\text { When global temp } \\
\text { increases by } 4^{\circ} \mathrm{C}\end{array}$ \\
\hline Piontek et al. (2013) & $\begin{array}{l}\text { River flow, crop yields, } \\
\text { ecosystems, malaria }\end{array}$ & $\begin{array}{l}\text { Stability in systems } \\
\text { vital to livelihoods }\end{array}$ & Temperature change & $\begin{array}{l}\text { Based on timing of } \\
\text { "crossing temp." }\end{array}$ \\
\hline Samson et al. (2011) & $\begin{array}{l}\text { Human population } \\
\text { distribution }\end{array}$ & $\begin{array}{l}\text { Implicit: Climate } \\
\text { stability }\end{array}$ & $\begin{array}{l}\text { Reductions in pop. } \\
\text { carrying capacity }\end{array}$ & 2050 \\
\hline $\begin{array}{l}\text { McGranahan et al. } \\
\text { (2007) }\end{array}$ & $\begin{array}{l}\text { Coastal populations } \\
\text { and lands }\end{array}$ & $\begin{array}{l}\text { Human populations } \\
\text { and land }\end{array}$ & Sea level rise & $\begin{array}{l}\text { When sea levels rise } \\
\text { by } 8-10 \mathrm{~m}\end{array}$ \\
\hline $\begin{array}{l}\text { CARE/Maplecroft and } \\
\text { Thow \& de Blois (2008) }\end{array}$ & Human populations & Human security & Climate hazards & $\begin{array}{l}\text { 1980-2000 hazards, } \\
2071-2100 \text { for GCMs }\end{array}$ \\
\hline Ericksen et al. (2011) & Agriculture & $\begin{array}{l}\text { Ag. productivity and } \\
\text { food security }\end{array}$ & $\begin{array}{l}\text { Changes in temperature } \\
\text { and rainfall }\end{array}$ & 2050 \\
\hline Fraser et al. (2012) & $\begin{array}{l}\text { Soil moisture and } \\
\text { agriculture }\end{array}$ & $\begin{array}{l}\text { Agricultural } \\
\text { productivity }\end{array}$ & $\begin{array}{l}\text { Reduced precipitation } \\
\text { and soil moisture }\end{array}$ & $\begin{array}{l}2045-2060 \text { (“2050s"), } \\
2075-2090 \text { (“2080s") }\end{array}$ \\
\hline Kok et al. (2011) & Rural livelihoods & $\begin{array}{l}\text { Ag. productivity and } \\
\text { food security }\end{array}$ & $\begin{array}{l}\text { Global environmental } \\
\text { change }\end{array}$ & Recent past \\
\hline Parish et al. (2012) & Water & $\begin{array}{l}\text { Water availability p.c. } \\
\text { above a threshold }\end{array}$ & $\begin{array}{l}\text { Climate change and } \\
\text { population growth }\end{array}$ & 2100 \\
\hline Döll (2009) & Ground water & $\begin{array}{l}\text { Ground water } \\
\text { recharge/availability }\end{array}$ & $\begin{array}{l}\text { Climate change and } \\
\text { population growth }\end{array}$ & $2041-70$ (“2050s") \\
\hline $\begin{array}{l}\text { De Stefano et al. } \\
\text { (2009) }\end{array}$ & River Basin & $\begin{array}{l}\text { Resilience to } \\
\text { precipitation variability }\end{array}$ & Precipitation variability & 2030 and 2050 \\
\hline \multicolumn{5}{|c|}{ Regional Hotpots Mapping Efforts } \\
\hline $\begin{array}{l}\text { Busby et al. (2011) } \\
\text { (Africa) }\end{array}$ & $\begin{array}{l}\text { Human populations } \\
\text { and governance sys. }\end{array}$ & $\begin{array}{l}\text { Political stability and } \\
\text { human security }\end{array}$ & $\begin{array}{l}\text { A range of climate } \\
\text { stressors }\end{array}$ & $\begin{array}{l}\text { Past climate } \\
\text { variability }\end{array}$ \\
\hline $\begin{array}{l}\text { Midgley et al. (2011) } \\
\text { (Southern Africa) }\end{array}$ & $\begin{array}{l}\text { Agriculture and } \\
\text { human health }\end{array}$ & Mostly food security & $\begin{array}{l}\text { Precip and temp change } \\
\text { (average and maximum) }\end{array}$ & 2050 \\
\hline $\begin{array}{l}\text { Abson et al. (2012) } \\
\text { (Southern Africa) }\end{array}$ & $\begin{array}{l}\text { Socio-ecological } \\
\text { systems }\end{array}$ & .. & $\begin{array}{l}\text { Aridity and rainfall } \\
\text { variability }\end{array}$ & .. \\
\hline $\begin{array}{l}\text { Liu et al. (2008) } \\
\text { (Africa) }\end{array}$ & Agriculture & Food security & $\begin{array}{l}\text { Impact ratios of climate } \\
\text { change } \& \mathrm{CO} 2 \text { fertil. }\end{array}$ & $2030 \mathrm{~s}$ \\
\hline $\begin{array}{l}\text { Thornton et al. (2008) } \\
\text { (Africa) }\end{array}$ & Agriculture & Food Security & $\begin{array}{l}\text { CC impacts on crop and } \\
\text { livestock productivity }\end{array}$ & 2050 \\
\hline $\begin{array}{l}\text { Hagenlocher et al. } \\
\text { (2013) (West Africa) }\end{array}$ & $\begin{array}{l}\text { Agriculture and sub- } \\
\text { sistence livelihoods }\end{array}$ & Food Security & $\begin{array}{l}\text { Changes and extremes } \\
\text { in climate parameters }\end{array}$ & $\begin{array}{l}\text { Climate trends and } \\
\text { variability since } 1970\end{array}$ \\
\hline $\begin{array}{l}\text { Yusuf and Francisco } \\
\text { (2009) (S.E. Asia) }\end{array}$ & .. & .. & Climate hazards & $\begin{array}{l}\text { Past climate } \\
\text { variability }\end{array}$ \\
\hline $\begin{array}{l}\text { ESPON Climate (2011) } \\
\text { (Europe) }\end{array}$ & Multiple & Multiple & $\begin{array}{l}\text { Extreme events and } \Delta \text { in } \\
\text { average conditions }\end{array}$ & $2071-2100$ \\
\hline $\begin{array}{l}\text { Schroter et al. (2005) } \\
\text { (Europe) }\end{array}$ & Ecosystems & Ecosystem services & $\begin{array}{l}\Delta \mathrm{s} \text { in } \mathrm{CO}_{2} \text { concentra- } \\
\text { tions, temp., and precip. }\end{array}$ & 2080 \\
\hline
\end{tabular}

".." = not specified; Key: system of analysis (what is vulnerable?), the valued attributes of concern (why is it important?), the external hazard (to what is the system vulnerable?), and a temporal reference (when?). Regional and global "expert judgment" mapping efforts are addressed in the supplementary online material (SOM). 
Revised Accepted Manuscript submitted to Climatic Change (8 August 2013).

Table 1. Hotspots mapping efforts reviewed for this paper (continued)

\begin{tabular}{|l|l|l|l|l|}
\hline \multicolumn{3}{|l|}{ Global Hotspots Mapping Efforts (expert judgment) } \\
$\begin{array}{l}\text { Warner et al. } \\
(2009 / 2012)\end{array}$ & Livelihoods & $\begin{array}{l}\text { Food security and in } \\
\text { situ adaptation }\end{array}$ & $\begin{array}{l}\text { An array of climate } \\
\text { impacts/rainfall variab. }\end{array}$ & Depends on the map \\
\hline Shubert et al. (2007) & Political systems & Security and stability & $\begin{array}{l}\text { Broad array of climate } \\
\text { impacts }\end{array}$ & $\begin{array}{l}\text { Mid to late } 21^{\text {st }} \\
\text { century }\end{array}$ \\
\hline $\begin{array}{l}\text { Scheffran and } \\
\text { Battaglini (2011) }\end{array}$ & Political systems & Security and stability & $\begin{array}{l}\text { Broad array of climate } \\
\text { impacts }\end{array}$ & $\begin{array}{l}\text { Mid to late } 21^{\text {st }} \\
\text { century }\end{array}$ \\
\hline
\end{tabular}

".." = not specified; Key: system of analysis (what is vulnerable?), the valued attributes of concern (why is it important?), the external hazard (to what is the system vulnerable?), and a temporal reference (when?). Regional and global "expert judgment" mapping efforts are addressed in the supplementary online material (SOM). 
Table 2. Summary table of global climate change hotspots mapping efforts

\begin{tabular}{|c|c|c|c|c|c|}
\hline \multirow{2}{*}{\multicolumn{2}{|c|}{ Primary focus/foci }} & Giorgi 2006 & Baettig et al. 2007 & Piontek et al. 2013 & Samson et al. 2011 \\
\hline & & $\begin{array}{l}\text { Climate change response by } \\
\text { region }\end{array}$ & $\begin{array}{l}\text { Increasing probabilities of } \\
\text { extreme warm/wet/dry years }\end{array}$ & $\begin{array}{l}\text { Multi-sector: Crops, water resources, } \\
\text { ecosystems, and human health }\end{array}$ & Impacts on human populations \\
\hline \multicolumn{2}{|l|}{ Audience } & Researchers (climate scientists) & Researchers and policy makers & Researchers & Researchers (ecologists) \\
\hline \multicolumn{2}{|c|}{ Geographic scope } & Global & Global & Global & Global \\
\hline \multicolumn{2}{|c|}{ Framework } & $\mathrm{n} / \mathrm{a}$ & $\mathrm{n} / \mathrm{a}$ & $\mathrm{n} / \mathrm{a}$ & $\mathrm{n} / \mathrm{a}$ \\
\hline \multicolumn{2}{|c|}{ Methods } & $\begin{array}{l}\text { Multi-model ensembles for } \\
\text { several IPCC scenarios were } \\
\text { used to assess changes in } \\
\text { regional mean precipitation, } \\
\text { mean surface air temperature, } \\
\text { and in the interannual variability } \\
\text { in precipitation and temperature }\end{array}$ & $\begin{array}{l}\text { SRES scenarios for GCMS were } \\
\text { used to assess changes in the } \\
\text { probability of warm, wet, and dry } \\
\text { years, and also by summer and } \\
\text { winter season }\end{array}$ & $\begin{array}{l}\text { GCMs simulating the highest RCP fed } \\
\text { Global Impact Models to identify } \\
\text { temperature thresholds for severe } \\
\text { impacts in four sectors. The "crossing } \\
\text { temperature" for severe impacts in } \\
\text { each sector were then mapped. }\end{array}$ & $\begin{array}{l}\text { Spatial representations of } \\
\text { population density and climate are } \\
\text { used together with climate model } \\
\text { outputs, based on an ecological } \\
\text { niche model }\end{array}$ \\
\hline \multicolumn{2}{|l|}{ Index } & $\begin{array}{l}\text { Regional Climate Change Index } \\
\text { (RCCI) }\end{array}$ & Climate Change Index (CCl) & Crossing temperature & $\begin{array}{l}\text { Climate-Demography Vulnerability } \\
\text { Index }\end{array}$ \\
\hline \multirow{6}{*}{$\begin{array}{l}\text { Regions } \\
\text { Identified }\end{array}$} & Africa & $\begin{array}{l}\text { North Africa (declines in mean } \\
\text { precipitation) }\end{array}$ & $\begin{array}{l}\text { All of sub-Saharan Africa, coastal } \\
\text { North Africa }\end{array}$ & $\begin{array}{l}\text { Highlands (Ethiopia, Rwanda, } \\
\text { Burundi, and Lesotho), Bight of } \\
\text { Benin, northern Guinea, eastern } \\
\text { Senegal, and western Mali }\end{array}$ & Most regions \\
\hline & Asia & Northeastern Asia & $\begin{array}{l}\text { China, Southeast Asia, } \\
\text { Northeastern Asia }\end{array}$ & $\begin{array}{l}\text { Turkey, Georgia, Ganges basin, } \\
\text { northeastern China and eastern } \\
\text { Russia }\end{array}$ & $\begin{array}{l}\text { Arabian Peninsula, Southeast } \\
\text { Asia }\end{array}$ \\
\hline & Europe & $\begin{array}{l}\text { Mediterranean (declines in } \\
\text { mean precip), North Eastern } \\
\text { Europe (increases in winter } \\
\text { precip and a strong regional } \\
\text { warming relative to the global } \\
\text { mean) }\end{array}$ & Spain, Italy, Arctic & Southern and eastern Europe & None \\
\hline & $\begin{array}{l}\text { Latin Am. } \\
\& \\
\text { Caribbean }\end{array}$ & $\begin{array}{l}\text { Central America (decrease in } \\
\text { precip, increase in precip } \\
\text { variability) }\end{array}$ & Northern South America & $\begin{array}{l}\text { Southern Amazon, Andean } \\
\text { Cordillera, and Pacific Coast of } \\
\text { Mexico, Guatemala and El } \\
\text { Salvador }\end{array}$ & $\begin{array}{l}\text { Central America, the Amazon } \\
\text { Basin }\end{array}$ \\
\hline & $\begin{array}{l}\text { North } \\
\text { America }\end{array}$ & $\begin{array}{l}\text { Northeastern quadrant (Canada } \\
\text { and US) }\end{array}$ & Arctic & $\begin{array}{l}\text { Great Lakes region, Gulf Coast, } \\
\text { Canadian Rockies }\end{array}$ & None \\
\hline & Oceania & Not identified & None & Southeastern Australia & Eastern Australia, SISes \\
\hline \multicolumn{2}{|l|}{ Funder } & N/A & $\begin{array}{l}\text { National Center of Competence } \\
\text { in Research, Swiss National } \\
\text { Science Foundation }\end{array}$ & $\begin{array}{l}\text { European Framework Programme, } \\
\text { UK, EU and other funding sources }\end{array}$ & $\begin{array}{l}\text { National Science and Engineering } \\
\text { Research Council of Canada }\end{array}$ \\
\hline
\end{tabular}


Revised Accepted Manuscript submitted to Climatic Change (8 August 2013).

Table 2. Summary table of global climate change hotspots mapping efforts (continued)

\begin{tabular}{|c|c|c|c|c|c|}
\hline & & McGranahan et al. 2007 & $\begin{array}{l}\text { CARE \& Maplecroft and Thow \& } \\
\text { de Blois } 2008\end{array}$ & Ericksen et al. 2011 & Fraser et al. 2012 \\
\hline \multicolumn{2}{|c|}{ Primary focus/foci } & Sea level rise & Natural hazard vulnerability & Food production & $\begin{array}{l}\text { Soil moisture and agriculture as it } \\
\text { affects wheat and maize } \\
\text { productivity }\end{array}$ \\
\hline \multicolumn{2}{|c|}{ Target audience } & Researchers (urban) & $\begin{array}{l}\text { Policymakers and humanitarian } \\
\text { actors }\end{array}$ & Agricultural research community & Agricultural research community \\
\hline \multicolumn{2}{|c|}{ Geographic scope } & Coastal Areas & The developing world & Tropical regions & Global \\
\hline \multicolumn{2}{|c|}{ Framework } & Focus on exposure and sensitivity & IPCC vulnerability framework & IPCC vulnerability framework & $\mathrm{n} / \mathrm{a}$ \\
\hline \multicolumn{2}{|l|}{ Methods } & $\begin{array}{l}\text { Overlay of coastal low elevation } \\
\text { band up to } 10 \mathrm{~m} \text { in elevation on a } \\
\text { population grid with urban and } \\
\text { rural identifiers }\end{array}$ & & $\begin{array}{l}\text { Combination of climate scenario } \\
\text { data, important climate thresholds } \\
\text { for agriculture, data on natural } \\
\text { resource degradation, and } \\
\text { indicators of food availability, } \\
\text { access, and utilization. }\end{array}$ & $\begin{array}{l}\text { Looks at change in growing season } \\
\text { soil moisture in relation to } \\
\text { adaptive capacity. Adaptive } \\
\text { capacity was modeled based on } \\
\text { socioeconomic variables that have } \\
\text { a high correlation with the crop } \\
\text { yield impacts of past drought } \\
\text { events. }\end{array}$ \\
\hline \multicolumn{2}{|l|}{ Index } & None & & $\begin{array}{l}\text { Maps are produced based on } \\
\text { combinations of high-low } \\
\text { exposure, sensitivity, and capacity }\end{array}$ & $n / a$ \\
\hline \multirow[t]{6}{*}{$\begin{array}{l}\text { Regions } \\
\text { Identified }\end{array}$} & Africa & Alexandria & $\begin{array}{l}\text { Sahel, Horn, Central Africa, } \\
\text { Southern Africa }\end{array}$ & $\begin{array}{l}\text { Portions of the Sahel (rainfall } \\
\text { variability) and moist tropical West } \\
\text { Africa and Rwanda/Burundi } \\
\text { (temperature thresholds) }\end{array}$ & Southern Africa (wheat and maize) \\
\hline & Asia & $\begin{array}{l}\text { Coastal cities including Shanghai, } \\
\text { Ho Chi Minh City }\end{array}$ & $\begin{array}{l}\text { Central Asia, Afghanistan and } \\
\text { Pakistan, Myanmar, Mongolia, } \\
\text { Borneo }\end{array}$ & $\begin{array}{l}\text { Most of India (especially for } \\
\text { rainfall variability but also } \\
\text { temperature thresholds) }\end{array}$ & Western China (wheat) \\
\hline & Europe & Amsterdam, Hamburg, London & & & Balkans (wheat and maize) \\
\hline & $\begin{array}{l}\text { Latin Am. \& } \\
\text { Caribbean }\end{array}$ & Buenos Aires, Rio De Janeiro & $\begin{array}{l}\text { Andes, Northern Mexico, } \\
\text { Argentina }\end{array}$ & None & Southern cone (wheat and maize) \\
\hline & $\begin{array}{l}\text { North } \\
\text { America }\end{array}$ & Miami, New Orleans & & & U.S. great plains (wheat) \\
\hline & Oceania & Sydney, Melbourne & & & None \\
\hline \multicolumn{2}{|l|}{ Funder } & $\begin{array}{l}\text { NASA Socioeconomic Data and } \\
\text { Applications Center }\end{array}$ & $\begin{array}{l}\text { UN Office for the Coordination of } \\
\text { Humanitarian Affairs and CARE }\end{array}$ & $\begin{array}{l}\text { Consultative Group for } \\
\text { International Agricultural Research } \\
\text { (CGIAR) with funding from aid } \\
\text { agencies }\end{array}$ & $\begin{array}{l}\text { UK National Environment Research } \\
\text { Council (NERC) }\end{array}$ \\
\hline
\end{tabular}


Table 2. Summary table of global climate change hotspots mapping efforts (continued)

\begin{tabular}{|c|c|c|c|c|}
\hline \multirow{2}{*}{\multicolumn{2}{|c|}{ Primary focus/foci }} & Kok et al. 2011 & Parish et al. 2011 & Döll 2009 \\
\hline & & $\begin{array}{l}\text { Vulnerability profiles based on resource } \\
\text { endowments, water, soil, and } \\
\text { development status }\end{array}$ & Water resources & Renewable groundwater resources \\
\hline \multicolumn{2}{|c|}{ Target audience } & Researchers (integrated assessment) & Researchers & Researchers \\
\hline \multicolumn{2}{|c|}{ Geographic scope } & Global & Global & Global \\
\hline \multicolumn{2}{|c|}{ Framework } & SUST vulnerability framework & Unclear & Unclear \\
\hline \multicolumn{2}{|l|}{ Methods } & $\begin{array}{l}\text { Integrated assessment models, geospatial } \\
\text { data, and cluster analysis to answer } \\
\text { questions: (1) What are main exposures, } \\
\text { vulnerable groups and their sensitivities? } \\
\text { (2) What are } V \text { creating mechanisms? (3) } \\
\text { Where do they manifest? (4) How will } \\
\text { future changes affect wellbeing? (5) What } \\
\text { coping/ adaptation responses are } \\
\text { possible? }\end{array}$ & GCMs coupled to hydrological models & $\begin{array}{l}\text { GCMs coupled to the WaterGap } \\
\text { hydrological model }\end{array}$ \\
\hline \multicolumn{2}{|l|}{ Index } & $\mathrm{N} / \mathrm{A}$ & Water stress & $\begin{array}{l}\text { Vulnerability index (human vulnerability } \\
\text { to climate change induced changes in } \\
\text { freshwater supply) }\end{array}$ \\
\hline \multirow{6}{*}{$\begin{array}{l}\text { Regions } \\
\text { Identified }\end{array}$} & Africa & $\begin{array}{l}\text { Extreme poverty in Sahel and Horn of } \\
\text { Africa }\end{array}$ & $\begin{array}{l}\text { North Africa (most scenarios), with } \\
\text { isolated spots in SS Africa }\end{array}$ & $\begin{array}{l}\text { North Africa, extreme western Africa } \\
\text { (Mauritania/Senegal), southwestern } \\
\text { Africa (Angola, Namibia, western South } \\
\text { Africa) }\end{array}$ \\
\hline & Asia & $\begin{array}{l}\text { Extreme poverty in Afghanistan; } \\
\text { Moderate to Extreme poverty in NW } \\
\text { China; Extreme overuse in Pakistan and } \\
\text { Western India, and in NE China }\end{array}$ & Eastern China (A2 scenario) & $\begin{array}{l}\text { Portions of Central Asia (the "stans") and } \\
\text { western China }\end{array}$ \\
\hline & Europe & None & None & Parts of southern Europe \\
\hline & Latin Am. \& Caribbean & Moderate poverty Andes & $\begin{array}{l}\text { Central America, Northeastern Brazil } \\
\text { (under A2 scenario) }\end{array}$ & $\begin{array}{l}\text { Northeastern Brazil, coastal Peru and } \\
\text { Chile }\end{array}$ \\
\hline & North America & $\begin{array}{l}\text { Marginal lands in West and Southwest } \\
\text { U.S. }\end{array}$ & West of the Great Lakes & $\begin{array}{l}\text { Ogalala aquifer in western Texas (in two } \\
\text { scenarios) }\end{array}$ \\
\hline & Oceania & $\begin{array}{l}\text { Marginal lands in West and Southwest } \\
\text { U.S., Marginal lands in Australia }\end{array}$ & None & Western Australia (in most scenarios) \\
\hline \multicolumn{2}{|l|}{ Funder } & $\begin{array}{l}\text { Netherlands Environmental Assessment } \\
\text { Agency (PBL) }\end{array}$ & $\begin{array}{l}\text { Oak Ridge National Laboratory, U.S. Dept } \\
\text { of Energy }\end{array}$ & Not listed \\
\hline
\end{tabular}


Figure 1. Regional Climate Change Index (RCCl)

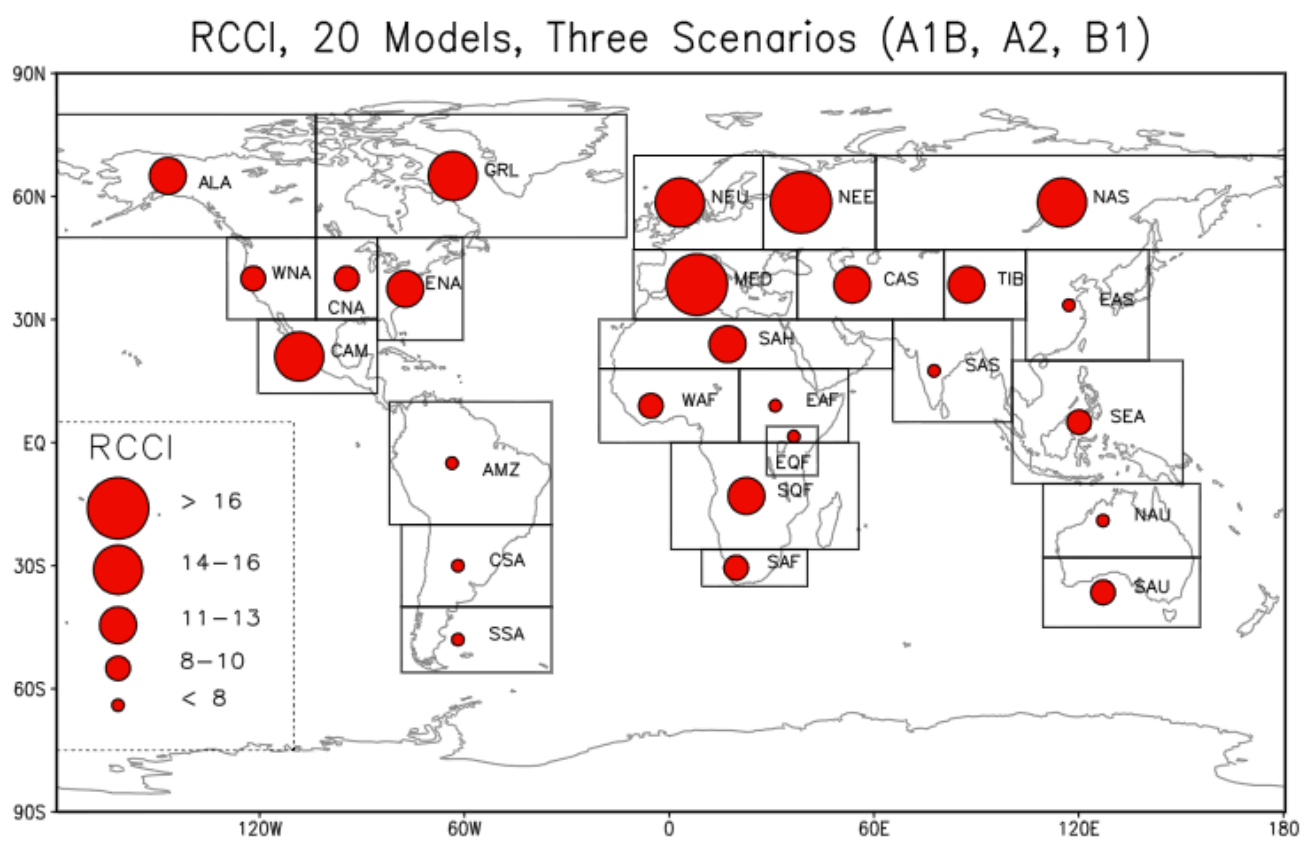

Source: Giorgi 2006

Figure 2. Climate Change Index (CCl)

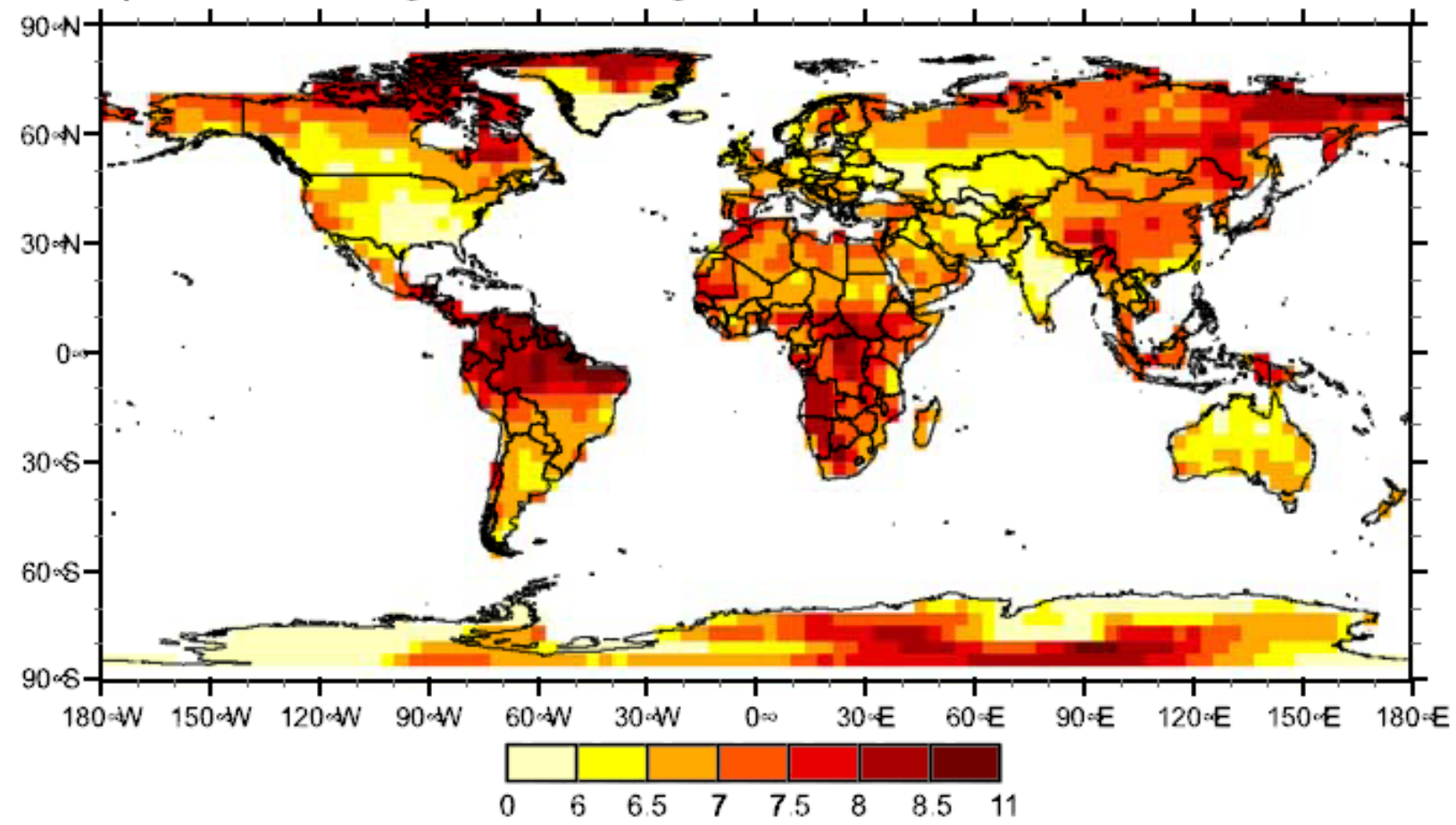

Source: Baettig 2007, pg. L01705 
Figure 3. The impact of a global temperature rise of $4^{\circ} \mathrm{C}$

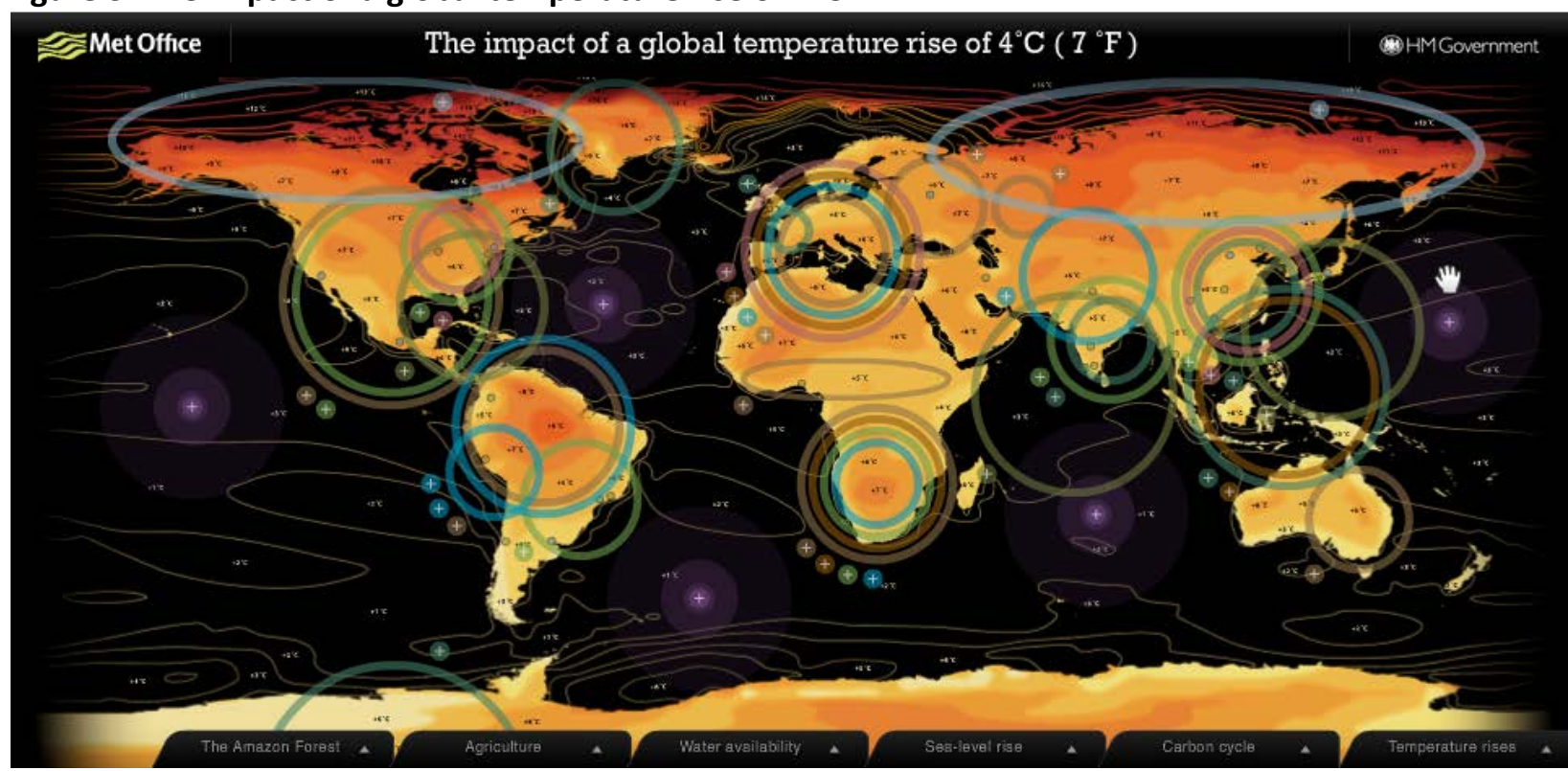

Source: UK Met Office, http://www.metoffice.gov.uk/climate-change/guide/impacts/high-end/map

Figure 4. Multisectoral hotspots of impacts for two (orange) and three (red) overlapping sectors

Notes: Multisectoral hotspots of impacts for two (orange) and three (red) overlapping sectors in the strict assessment, with $50 \%$ of GIM-GCM combinations agreeing on the threshold crossing in each sector, for a GMT change of up to $4.5^{\circ} \mathrm{C}$. An overlap of all four sectors does not occur in the strict assessment. Regions in light gray are regions where no multisectoral overlap is possible. The dark gray shows the additional regions affected by multisectoral pressures under the worst-case assessment, where a minimum of $10 \%$ of all sectoral GIM-GCM combinations have to agree on the threshold crossing.

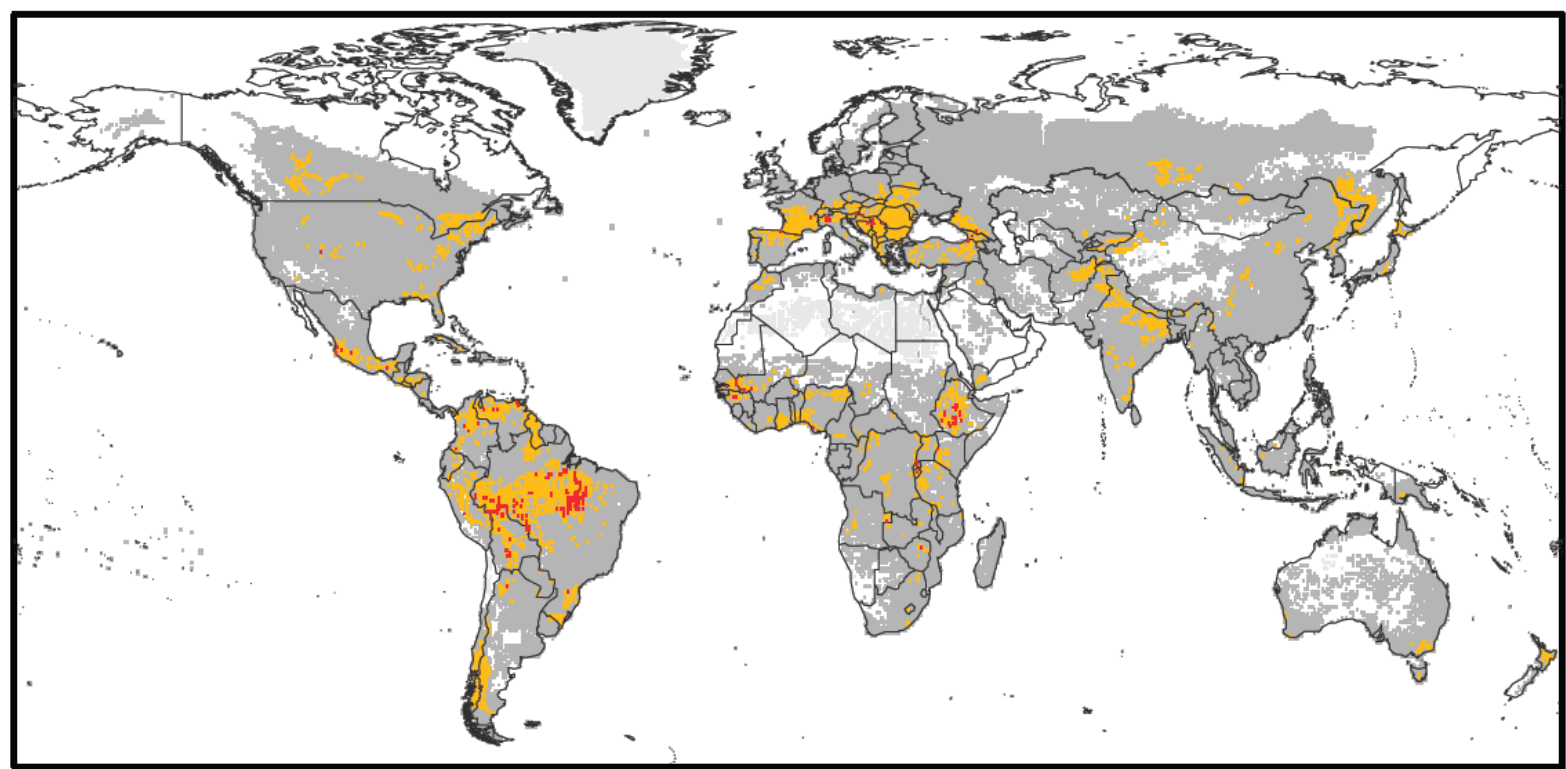

\section{2 overlapping sectors $\quad 3$ overlapping sectors}

Source: Piontek et al. 2013, Figure 2. 
Figure 5. Climate Vulnerability Index (CVI)

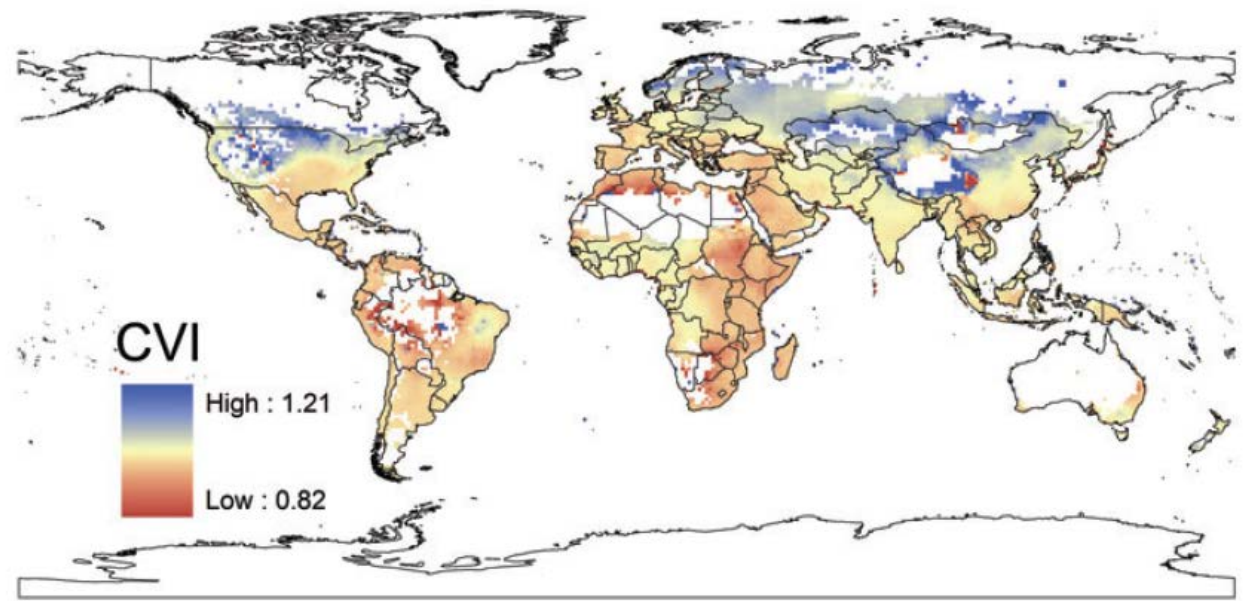

Figure 4 Climate vulnerabilities index (CVI) expressed as climate-consistent annual growth rate $\left(\lambda_{;}\right.$; see equation 4$)$ based on current human density-climate relationships (Fig. 3) and a 2050 climate forecast (Fig. S3a). Climate-consistent annual growth rates of less than one, indicated in red, represent negative growth and high vulnerabilities, while changes in annual growth rates of greater than one, indicated in blue, represent positive growth and low vulnerabilities. White regions correspond to human density values of zero in the global gridded population database.

Source: Samson et al. 2011, Figure 4.

Figure 6. Climate-Demography Vulnerability Index (CDVI)

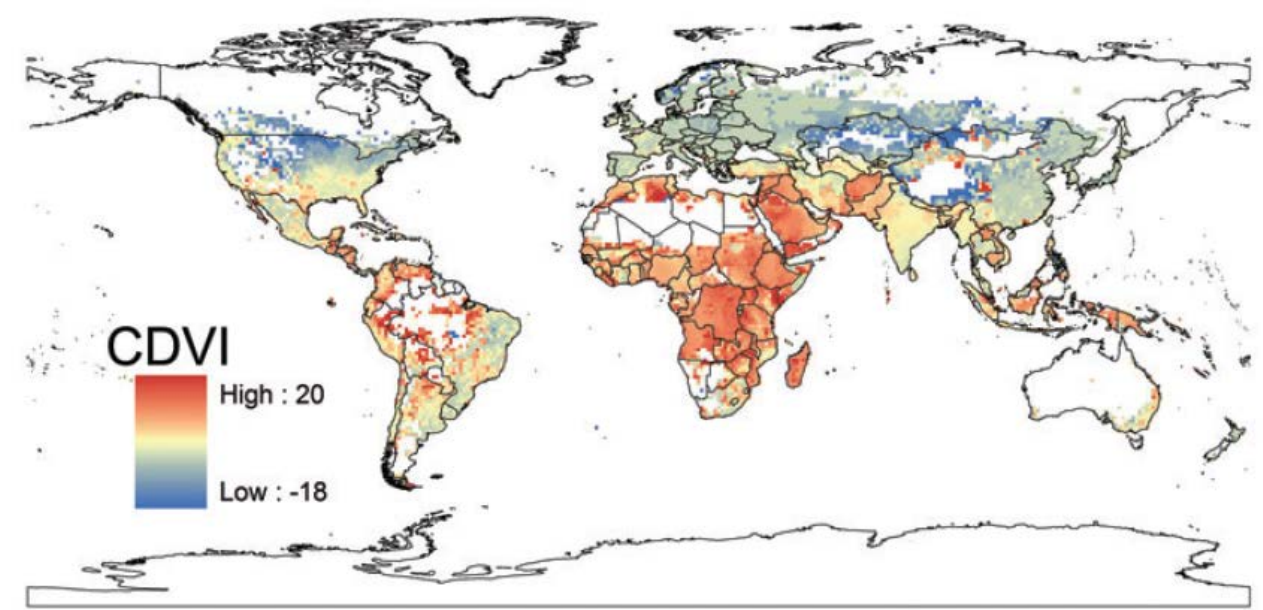

Figure 5 Global climate-demography vulnerability index (CDVI) estimated by subtracting CVI (Fig. 4) from demographic annual growth rates (Fig. S4), expressed as annual growth rates of human population density (see equation 5). Highly negative values, indicated in blue, represent low-vulnerability situations where current demographic growth is much lower than climate-consistent population growth, while highly positive values, indicated in red, represent high-vulnerability situations where current demographic growth vastly exceeds climate-consistent population growth. White regions correspond to human density values of zero in the global gridded population database.

Source: Samson et al. 2011, Figure 5 
Figure 7. Low elevation coastal zone in coastal China

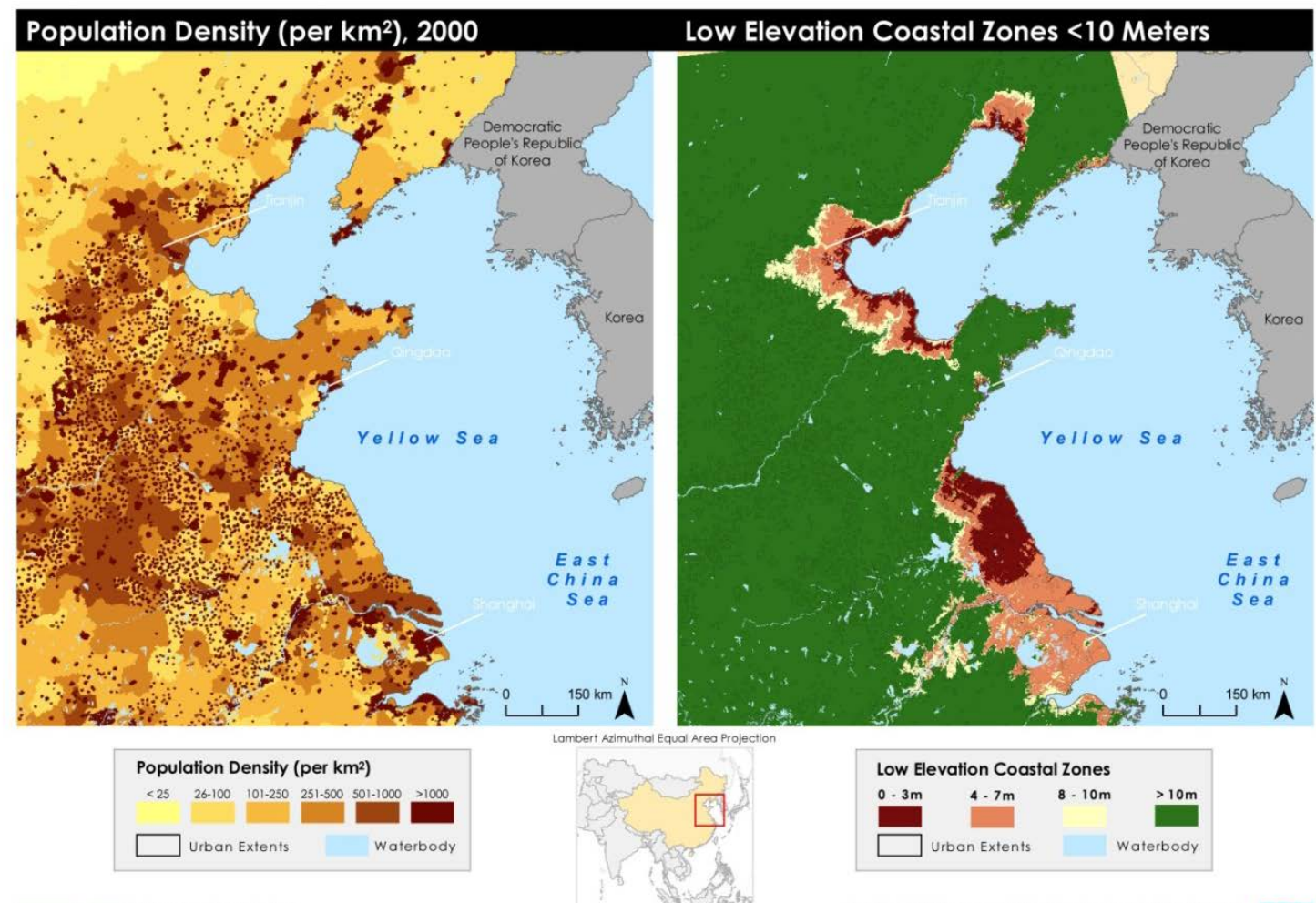

(c) (1)

Source: McGranahan et al. 2007b.

Figure 8. Overall human vulnerability to humanitarian crises

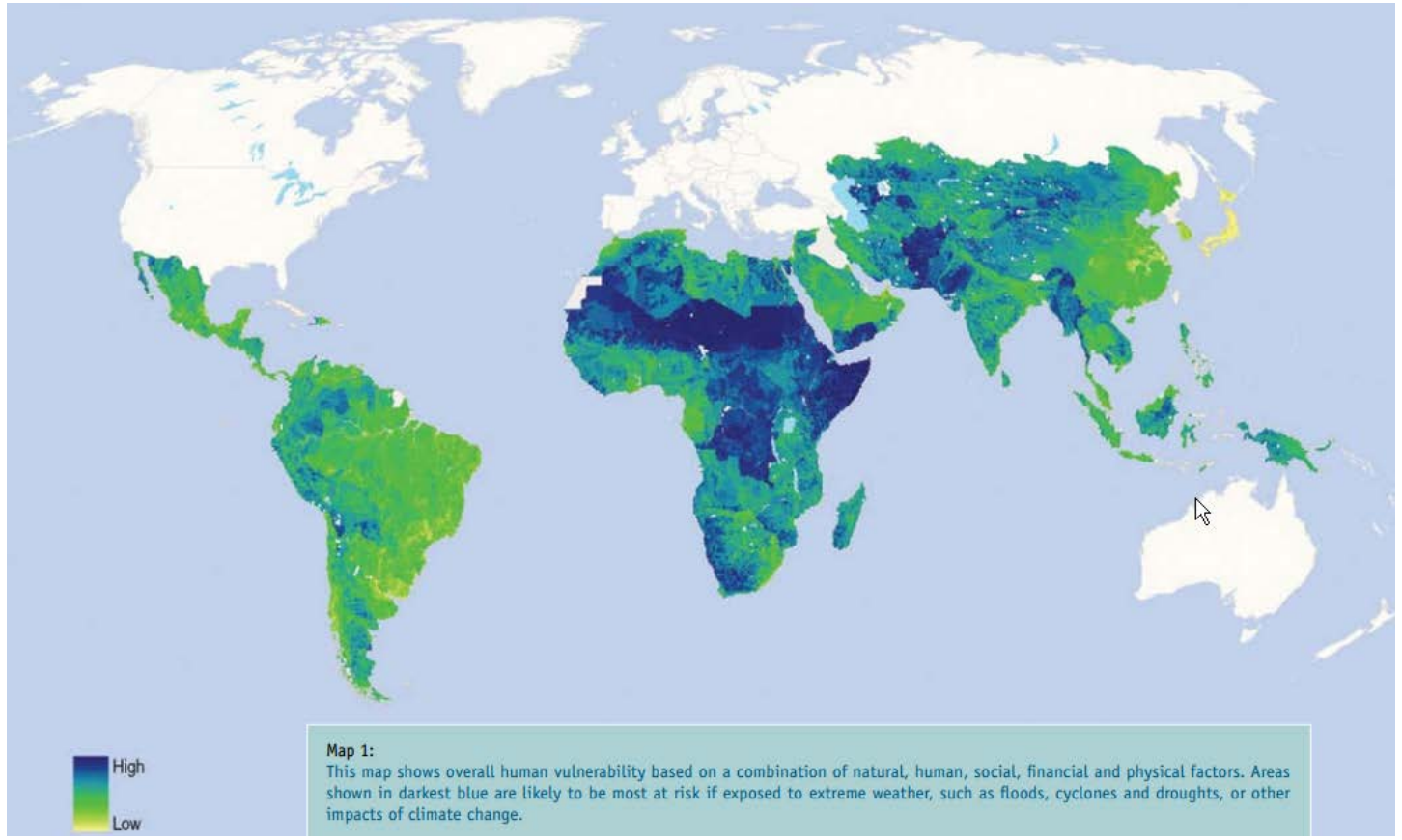

Source: CARE and Maplecroft 2008. 
Figure 9 . Vulnerability to maximum daily growing season temperature exceeding $30^{\circ} \mathrm{C}$

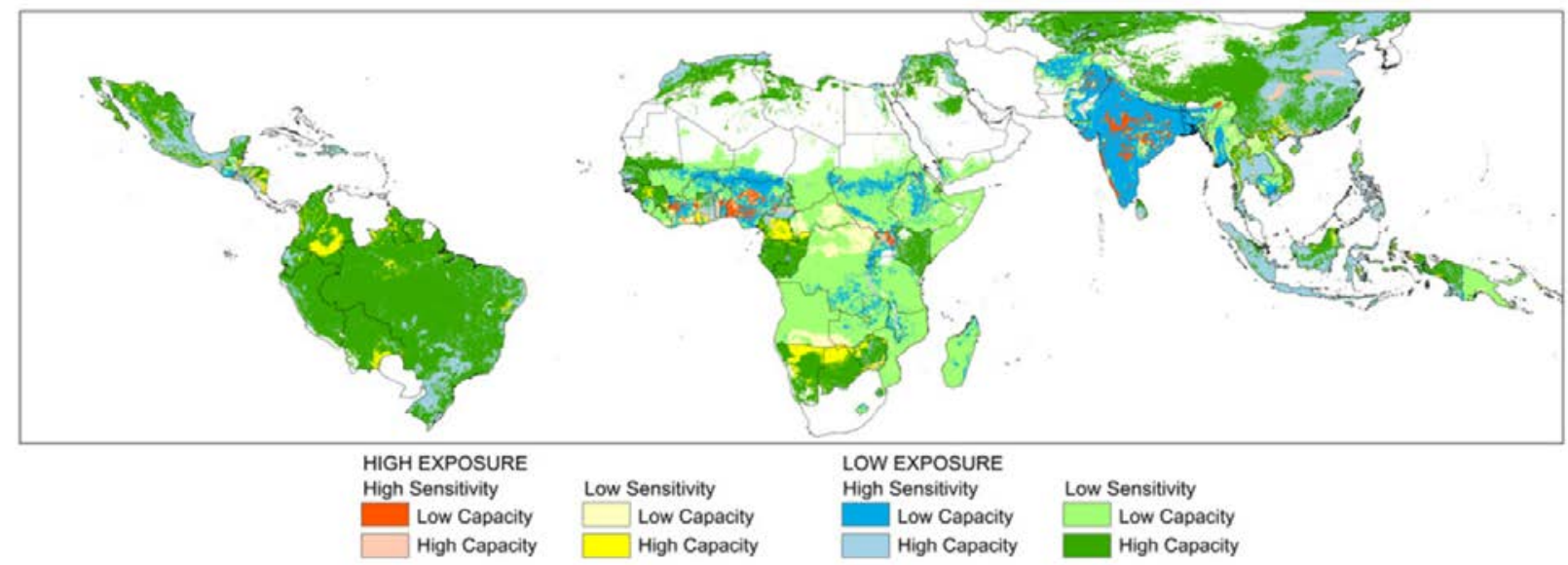

Source: Ericksen et al. 2011, map 4.8, p. 32.

Figure 10. Vulnerability hotspots for wheat and maize (circled)

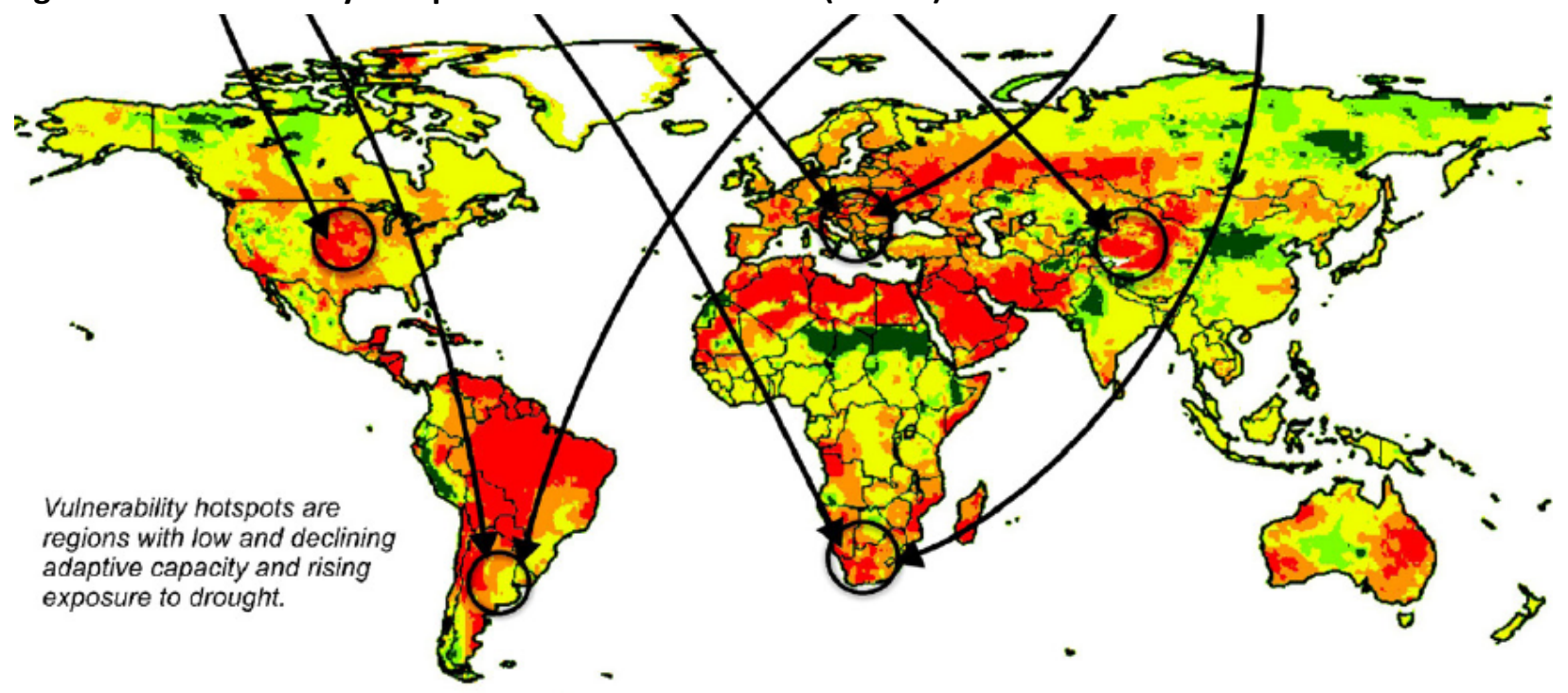

Source: Fraser et al. 2012, Figure 4. 
Figure 11. Geographical distribution of vulnerability profiles

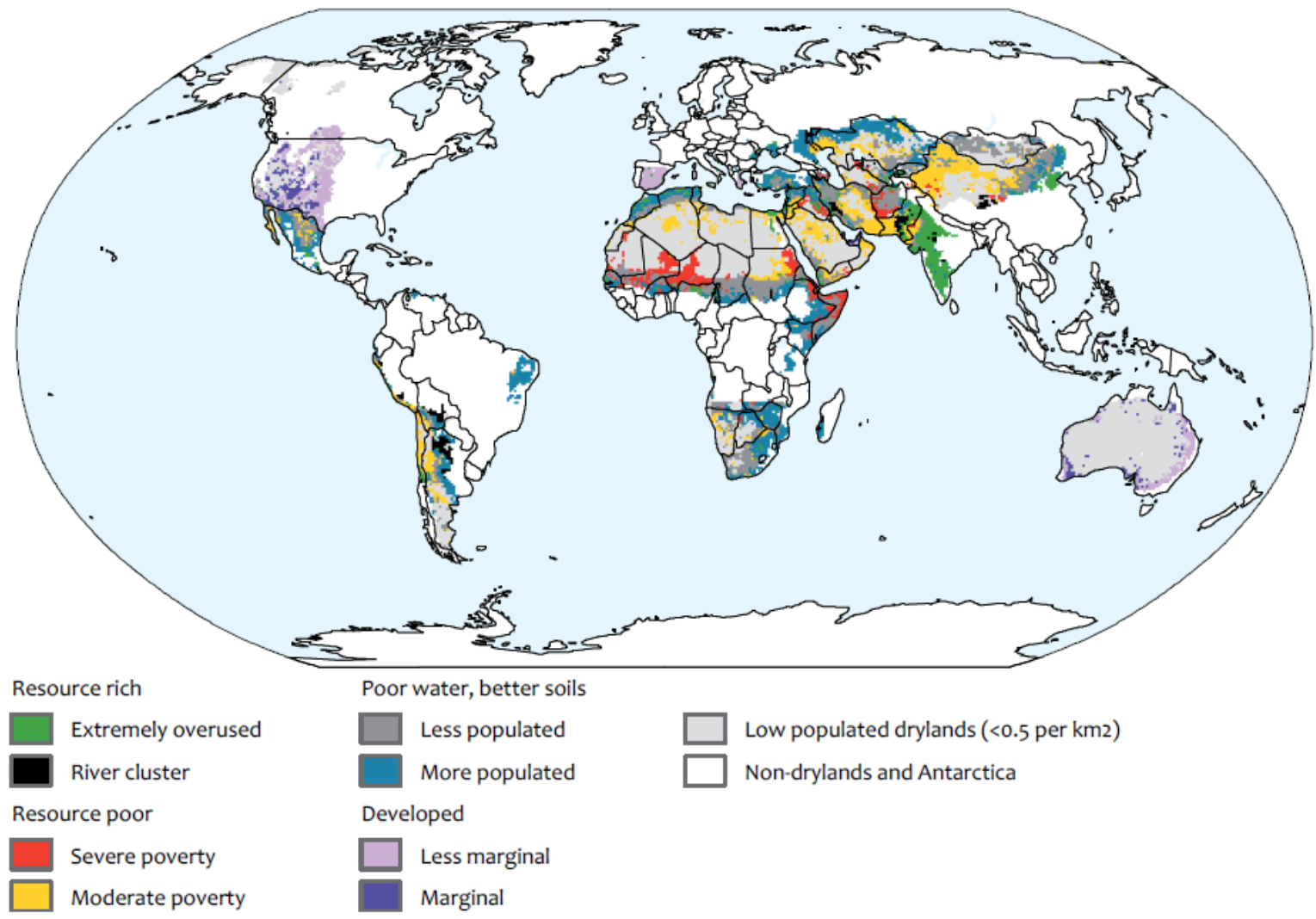

Source: Kok et al. 2010, Figure 2.9.

Figure 12. Projected 'Hotspots" of water stress change

Notes: Changes in water stress by 2100 are calculated by global water shed under IPCC SRES A1B, B1, A2, and A1F1 scenarios (top to bottom), a range of low to high emission scenarios. Red colors indicate areas of increasing water stress and blue colors indicate areas of decreasing water stress.

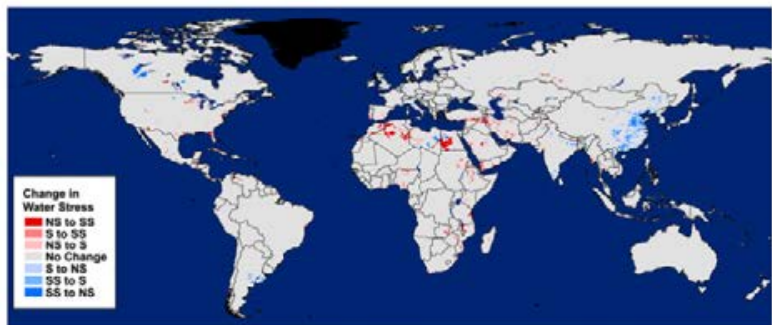

Projected Changes in Water Stress by 2100 (A1B Scenario)

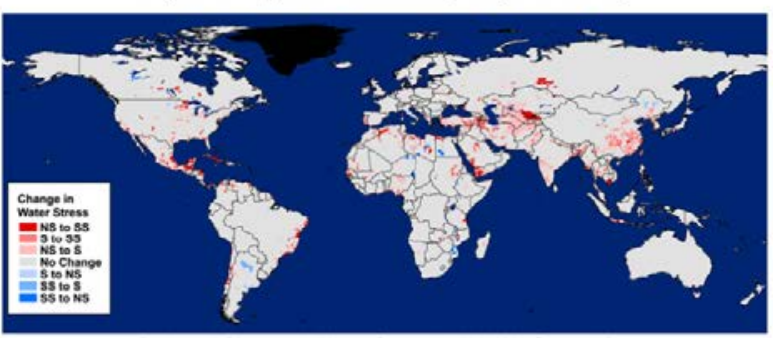

Projected Changes in Water Stress by 2100 (A2 Scenario)

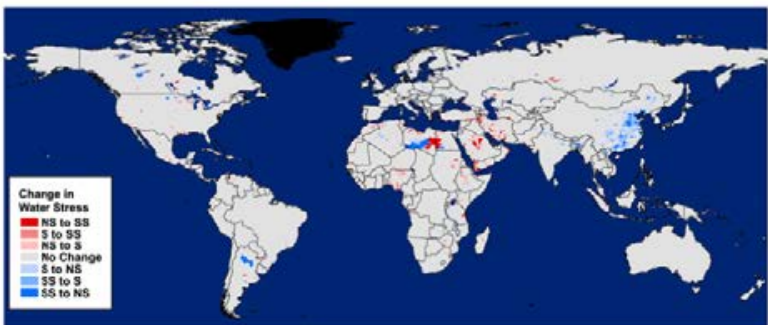

Projected Changes in Water Stress by 2100 (B1 Scenario)

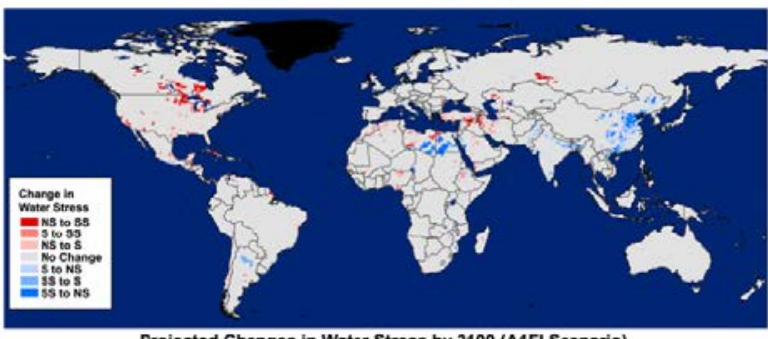

Projected Changes in Water Stress by 2100 (A1FI Scenario) 
Source: Parish et al. 2012, Figure 6.

Figure 13. Global Distribution of Seven Syndromes of Global Environmental Change

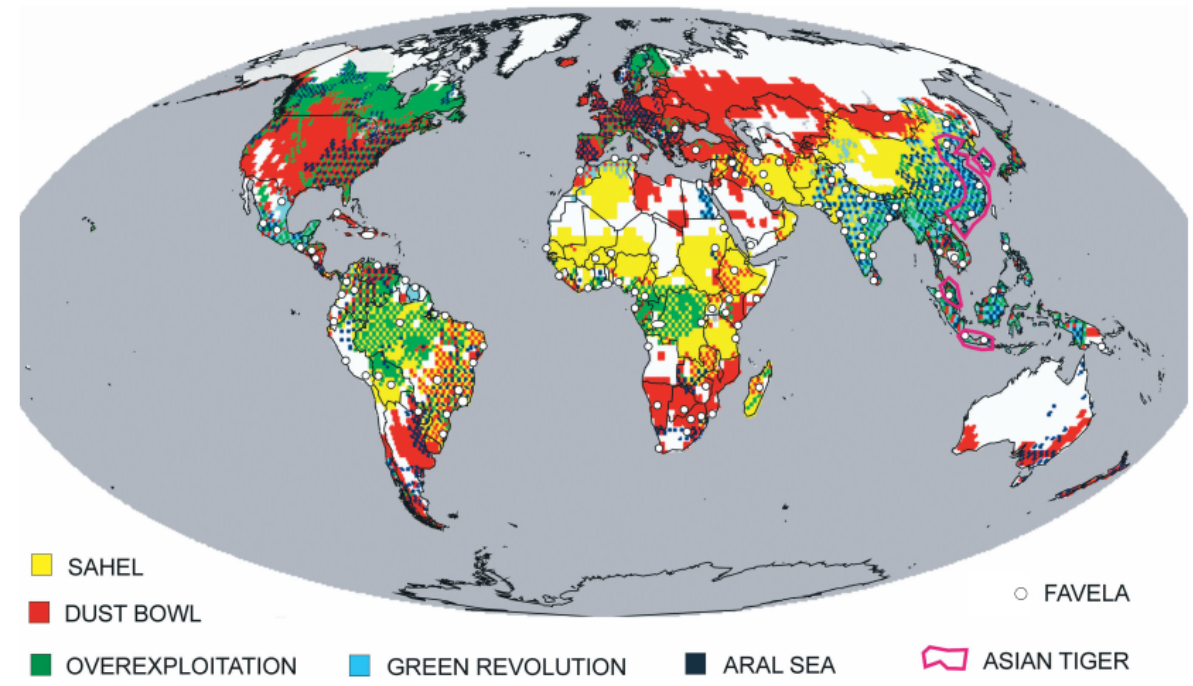

Figure 2. Global distribution of seven syndromes. Syndrome names are given in the legend. Simultaneous occurrence of more than one syndrome in a spatial map unit ( 2 degrees of latitude by 2 degrees of longitude) is symbolised by a chequered pattern combining the colours of the syndromes involved (the finest original resolution for a single syndrome is 0.5 by 0.5 degrees). The light grey land areas are either syndrome-free with respect to the seven investigated syndromes, or potential syndromes could not be identified because of significant gaps in data availability. While the indication of the Dust Bowl, the Green Revolution and the Asian Tiger Syndromes has global coverage, some gaps exist for the other four syndromes due to absence of or unreliable data. This refers, for example, to all four syndromes with respect to Russia, to the Aral Sea and Sahel Syndromes in some regions of Africa and the Overexploitation Syndrome in parts of Central America.

Source: Lüdeke et al. 2004, Figure 2.

Figure 14. Somalia's Composite Vulnerability Index

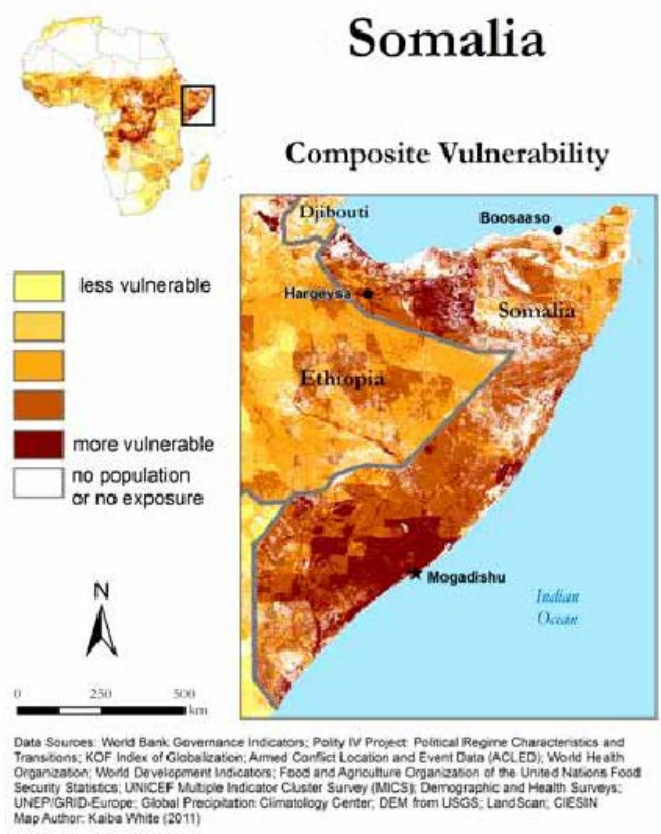

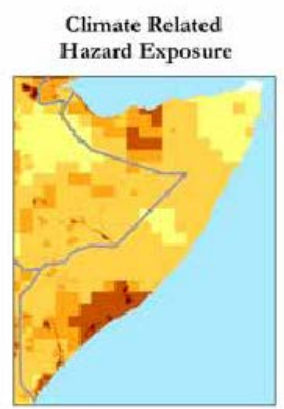

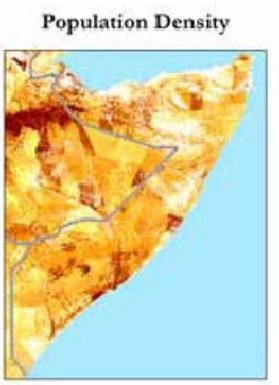

Household and Comm

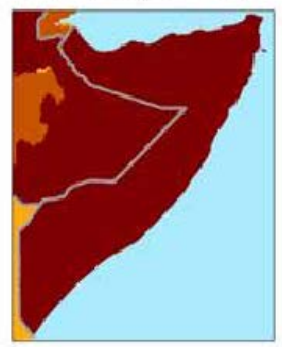

Governance and Violence

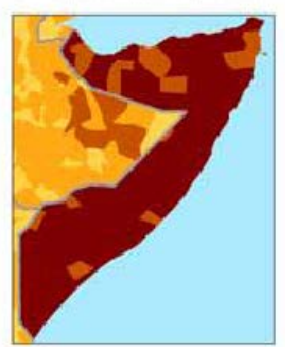

Source: Busby et al. 2011, Figure 2. 
Figure 15. Vulnerability hotspots (a. 2008 and b. 2050). (Red values indicate hotspots where people are most likely to be most in need of help adapting to climate stressors, while the blue areas indicate areas of resilience.)

a.

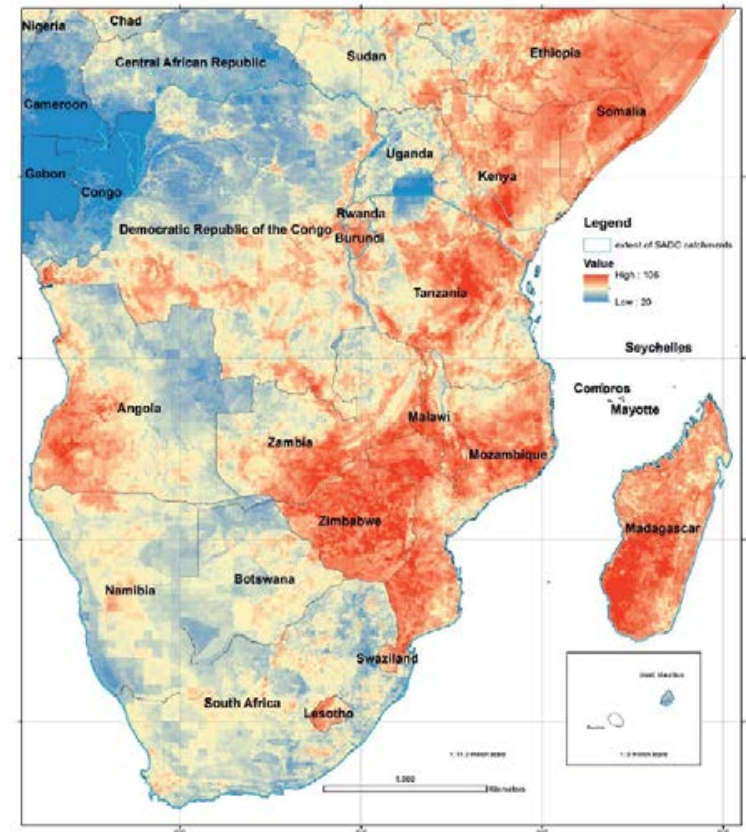

b.

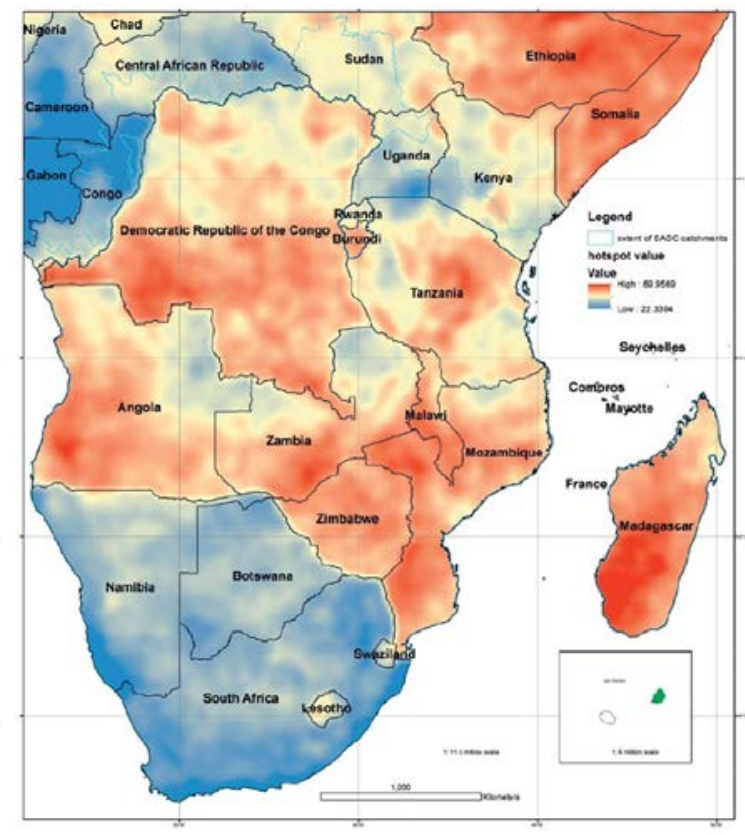

Source: Midgley et al. 2011, Figures 6 and 11.

Figure 16. Comparison of vulnerability maps produced by Midgley et al. and Abson et al. (data and methods are discussed in Section 1.1 of the SOM)
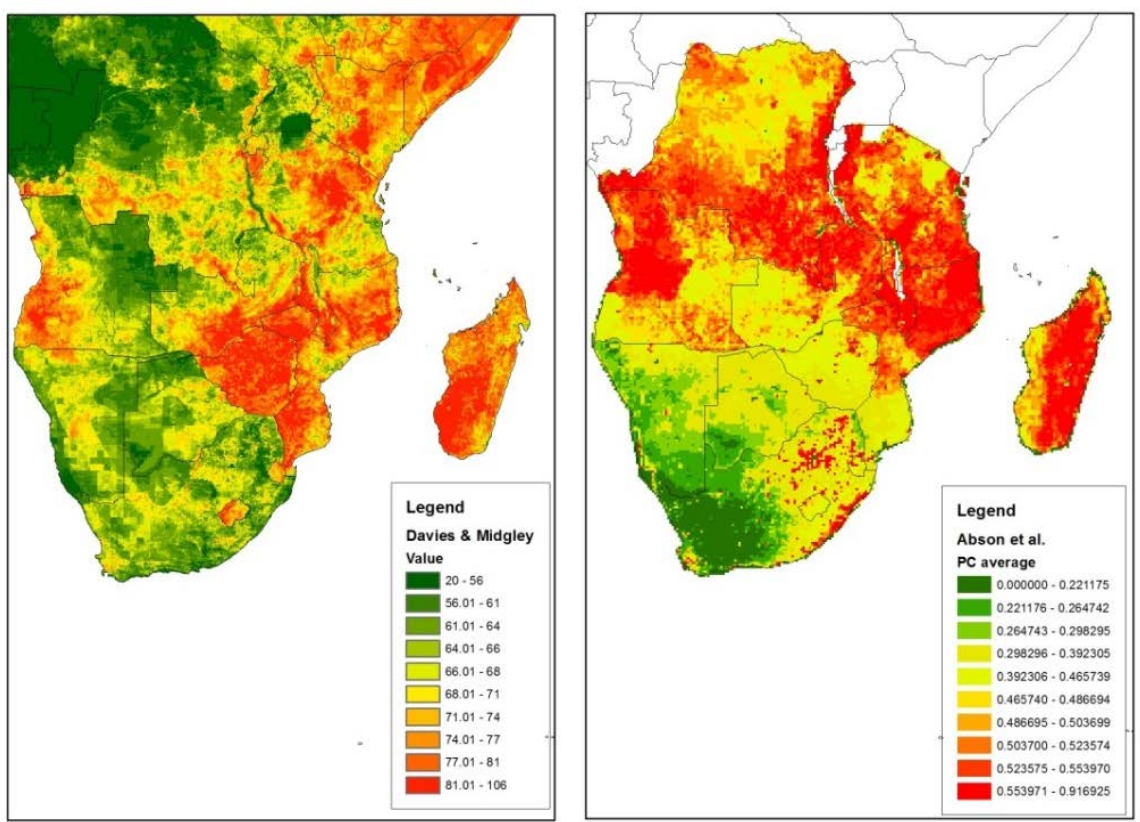

Sources: Davies \& MIdgley 2010 and Midgley et al. 2011 (left) and Abson et al. 2012a (right). 
Figure 17. Number of people with current undernutrition problems in relation to future potential hotspots of food insecurity in the 2030s

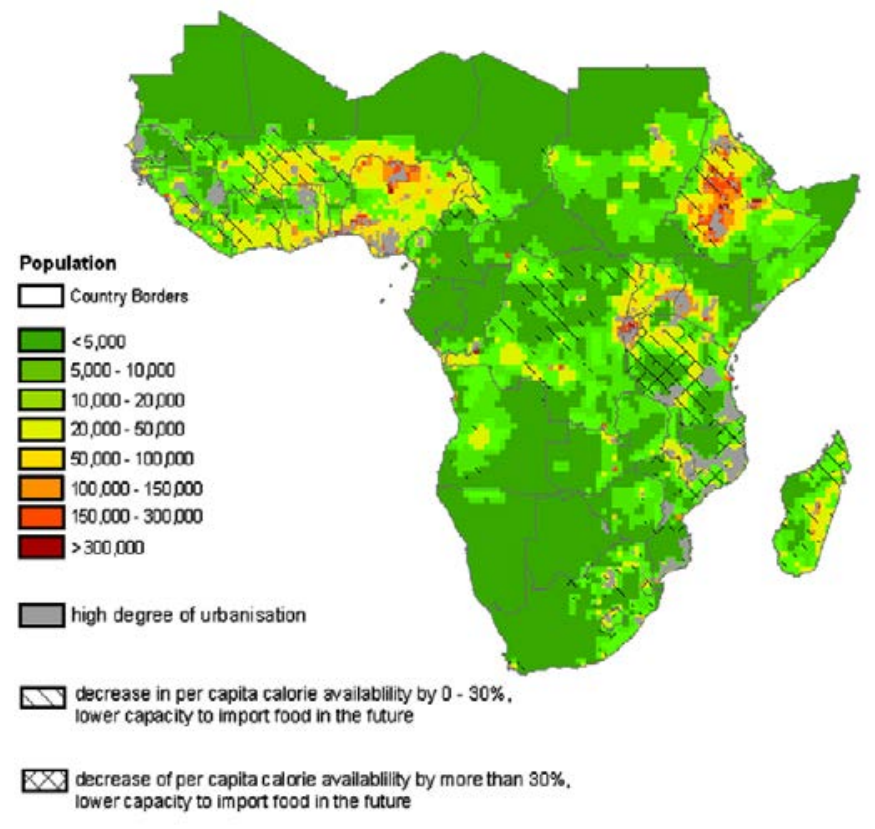

Source: Liu et al. 2008, Figure 13.

Figure 18. Index of Cumulative Climate Change Impact

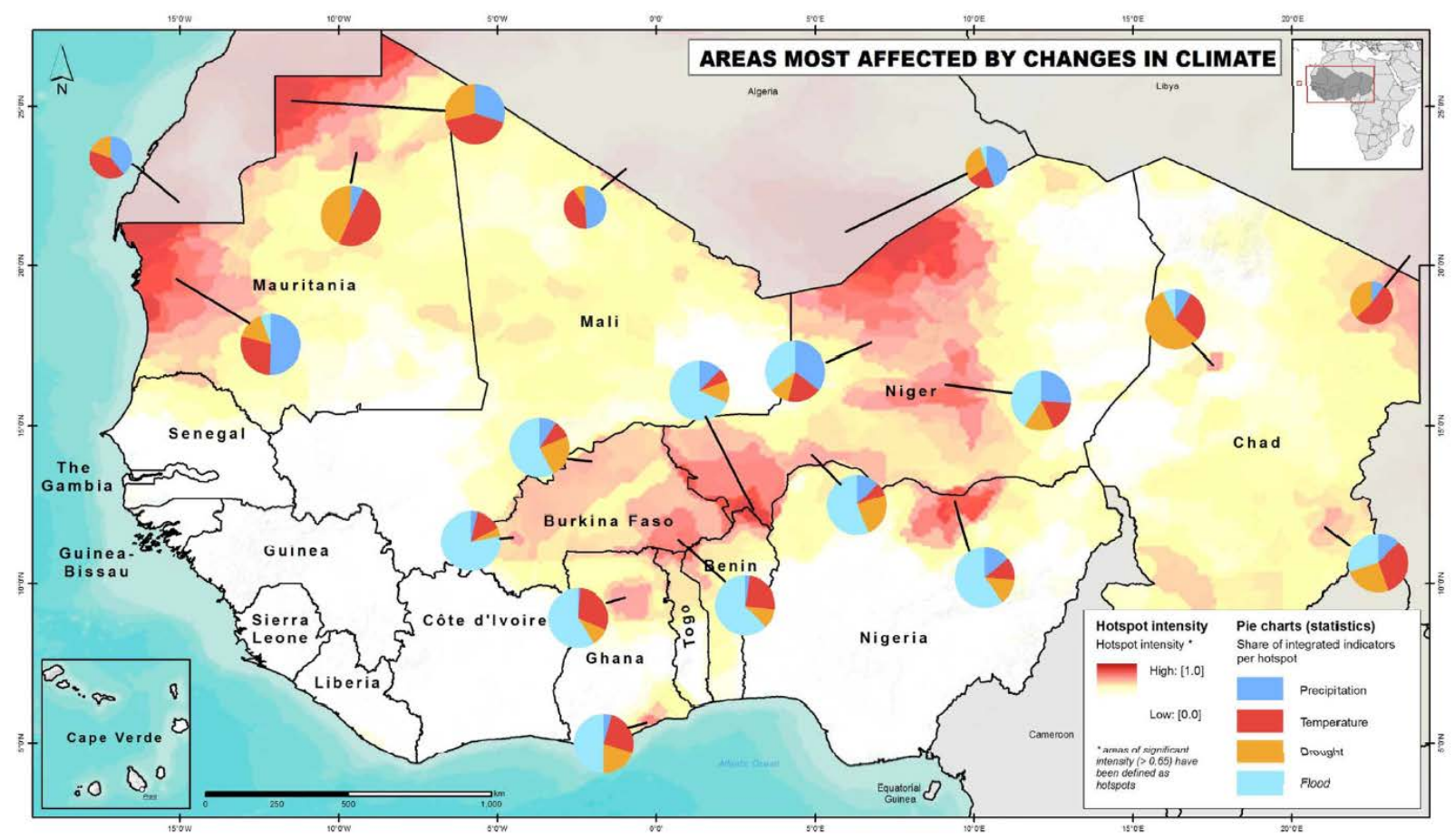

Source: Hagenlocher et al. 2013, Figure 4. 
Figure 19. Climate Change Vulnerability for Southeast Asia

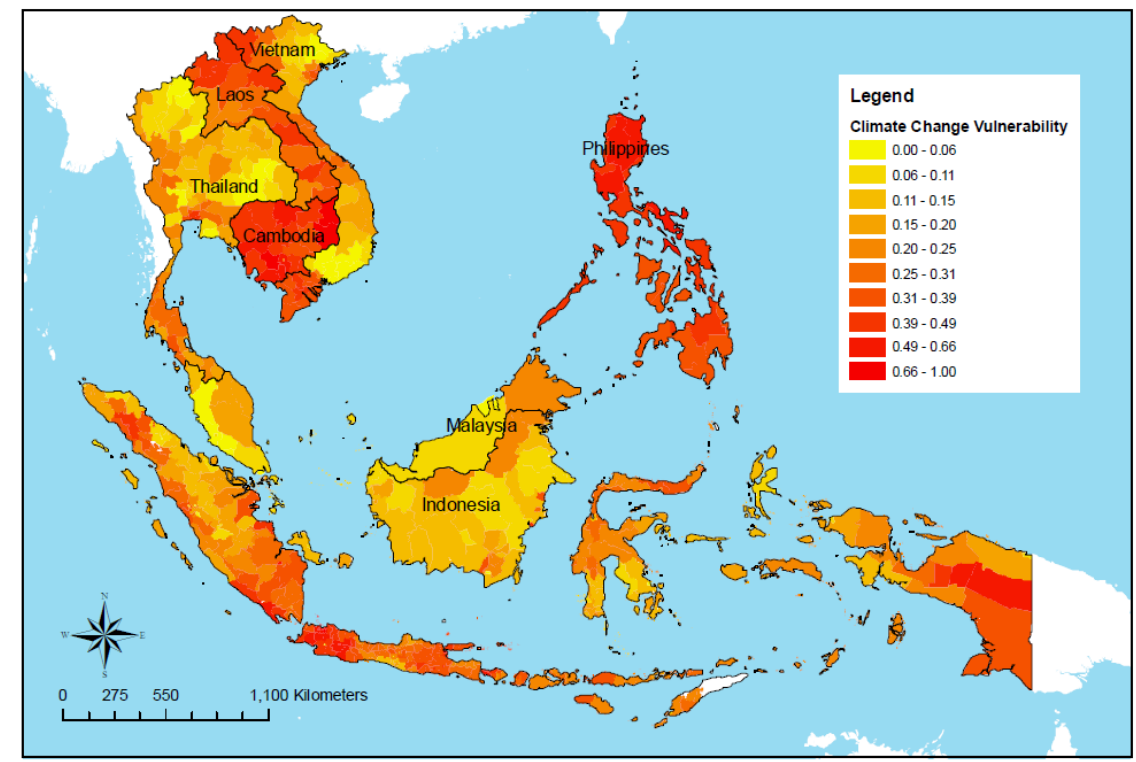

Source: Yusuf and Francisco 2009.

Figure 20. ESPON Europe assessment 


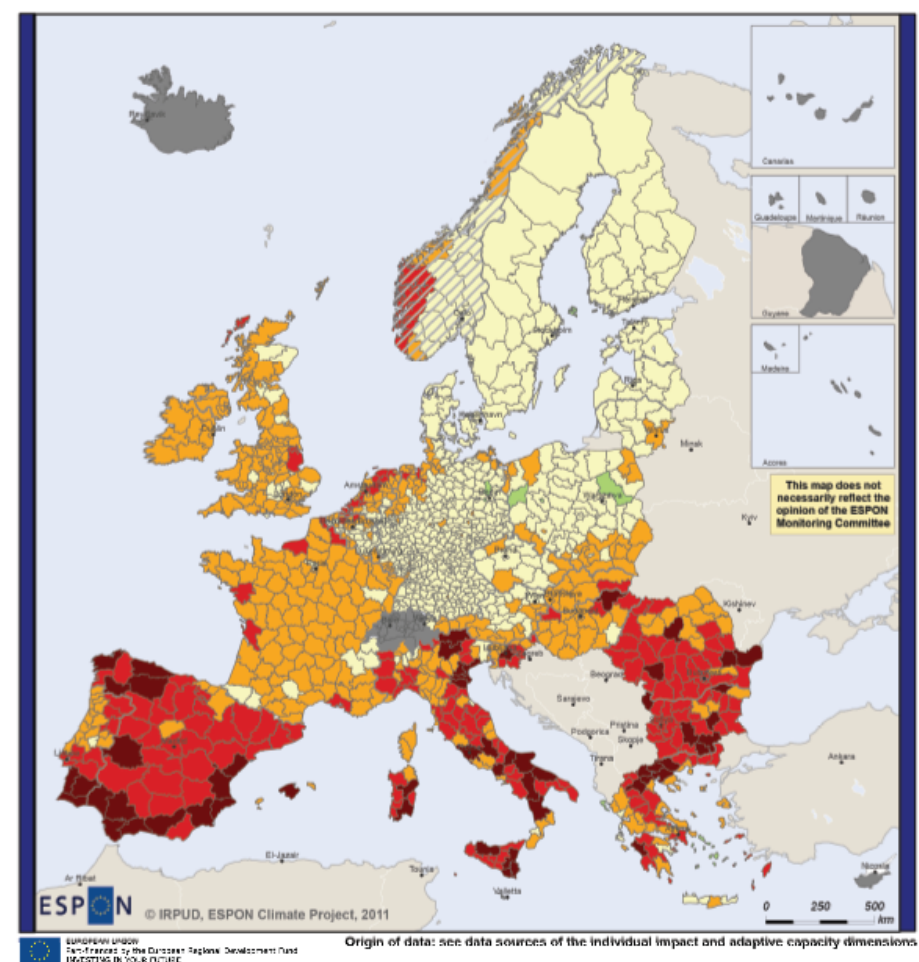

Potential vulnerability to climate change

$$
\begin{aligned}
& \text { highest negative impact }(0.5-1.0) \\
& \text { medium negative impact }(0.3-<0.5) \\
& \text { low negative impact }(0.1-<0.3) \\
& \text { noimarginal impact }(>-0.1-<0.1) \\
& \text { low positive impact }(-0.1--0.25) \\
& \text { no data* }
\end{aligned}
$$

U//, recuced data"

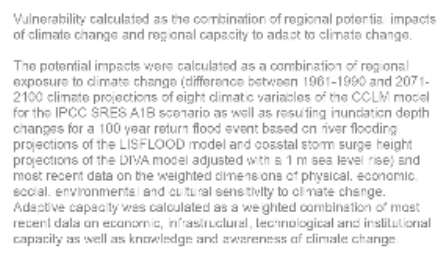

Source: ESPON Climate 2011, p.24.

Figure 21. Projected percent change in rainfall runoff by $\mathbf{2 0 8 0}$ overlaid on population distribution Notes: Map insets are for (clockwise from top): rainfall runoff (1960-1980 baseline), cyclone frequency (19802000), and rainfed agricultural areas. 


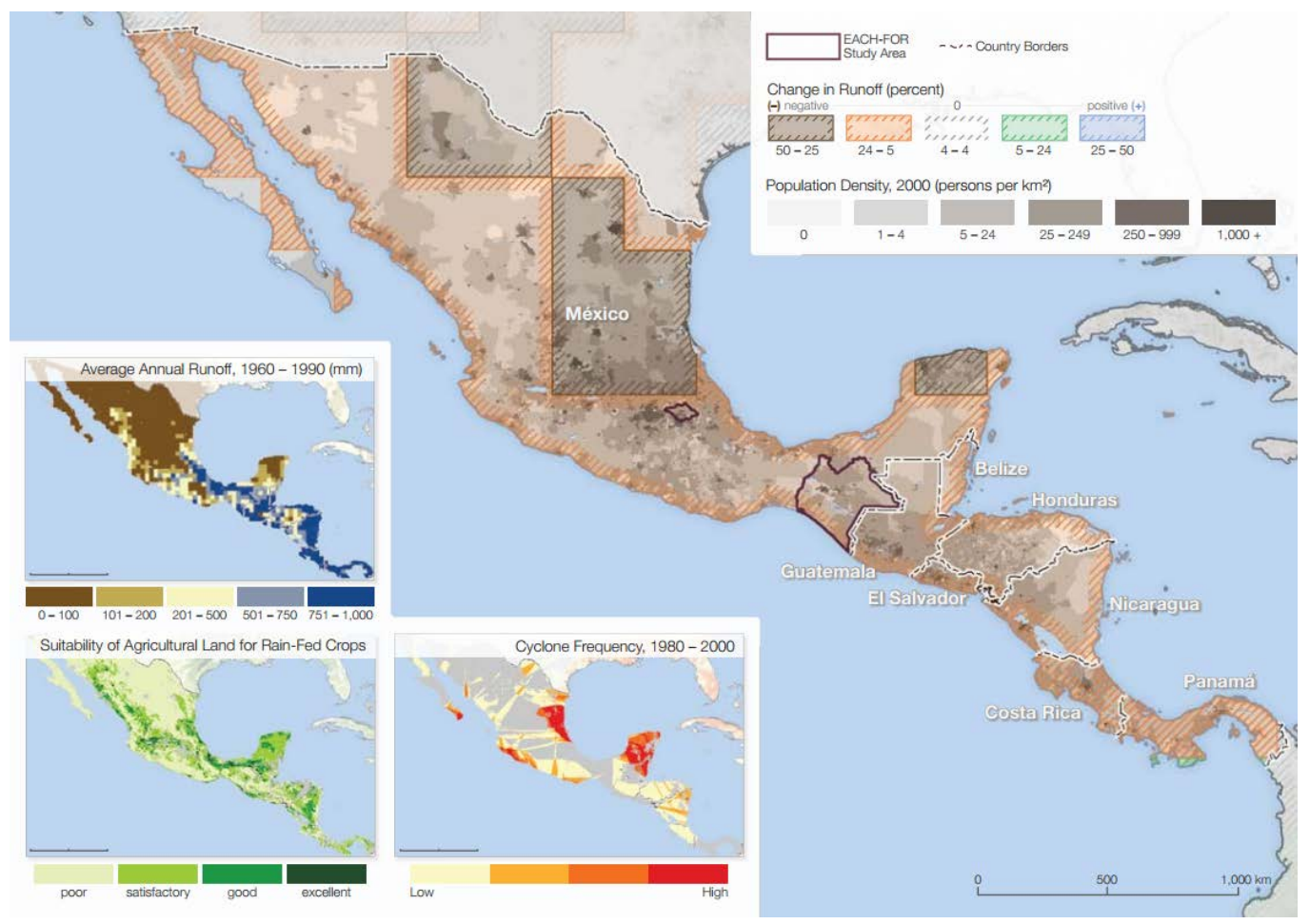

Source: Warner et al. 2009, p.4.

\section{Figure 22. Climate Change and Migration Hotspots}

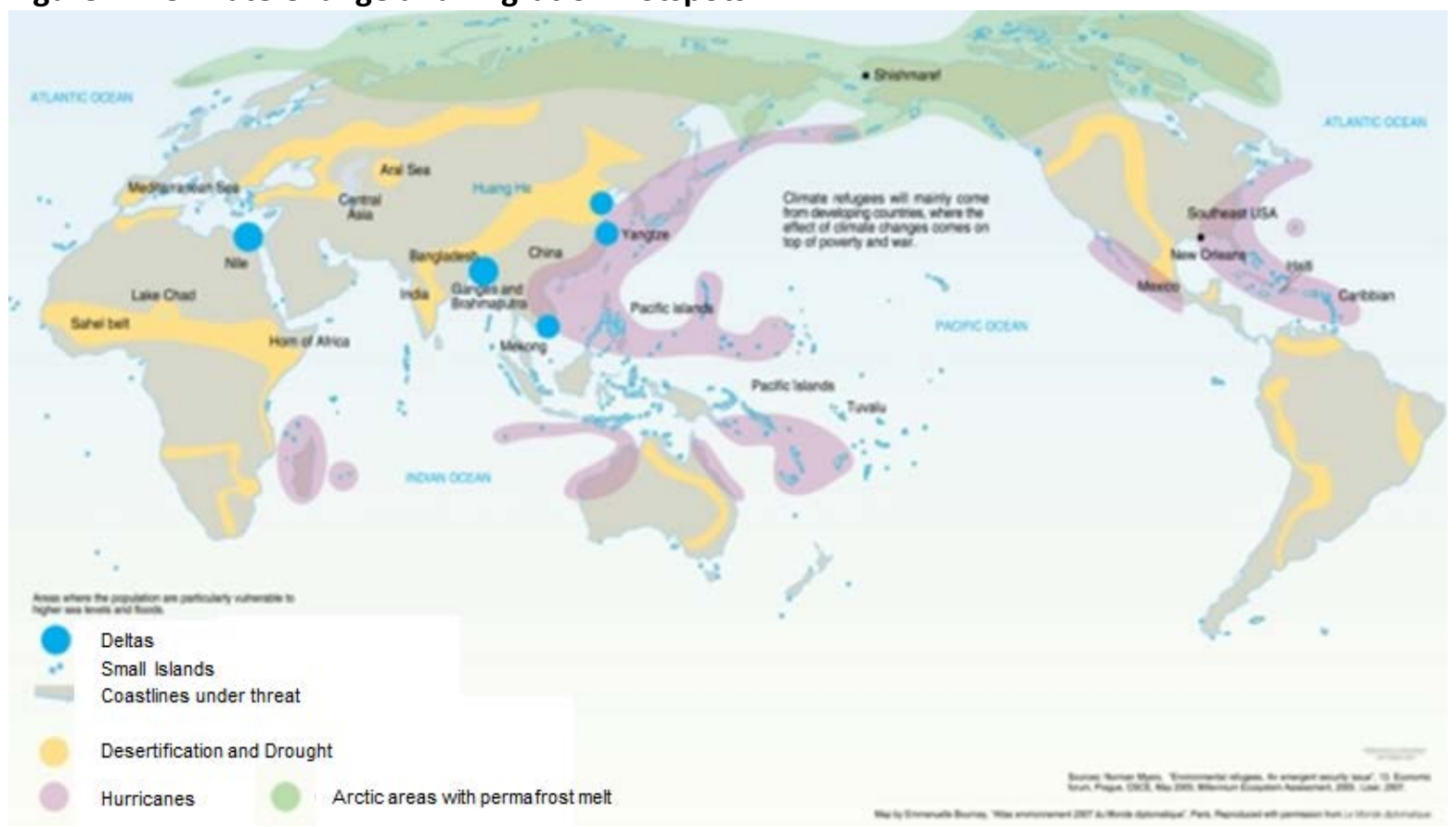

Source: Emmanuelle Bournay, UNEP-GRID Arendal, "Fifty million climate refugees by 2010" http://www.grida.no/graphicslib/detail/fifty-million-climate-refugees-by-2010 71db 
Figure 23. Security risks associated with climate change: Selected hotspots

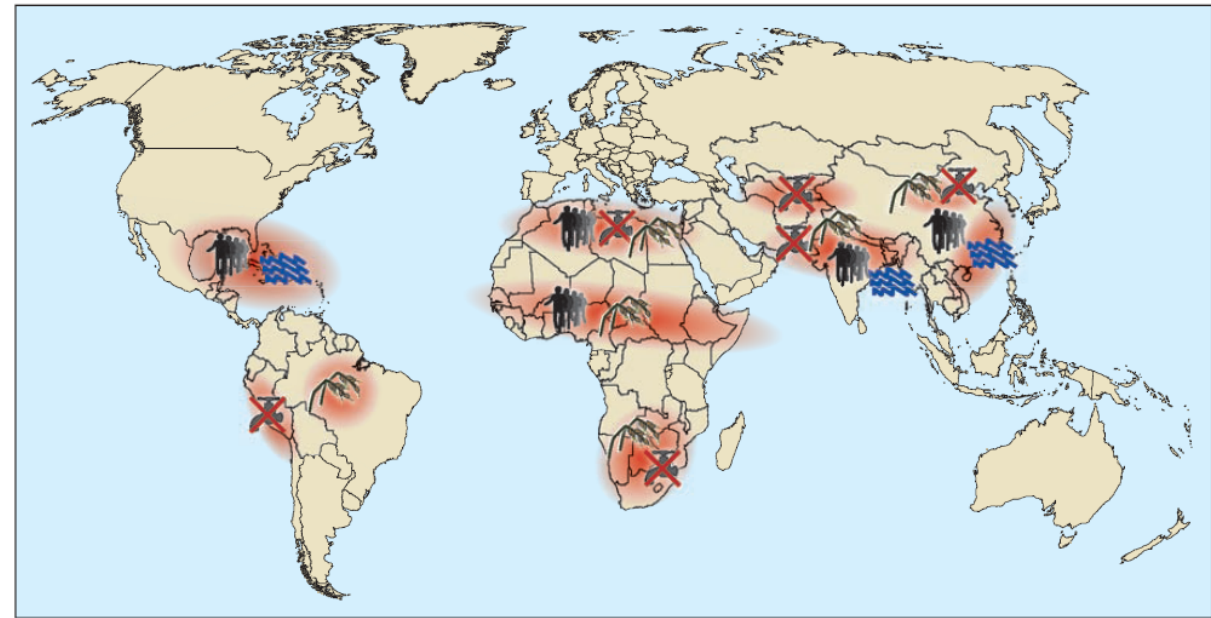

Conflict constellations in selected hotspots

Climate-induced degradation

Climate-induced decline
in food production

Hotspot

of freshwater resources

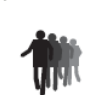

Environmentally-induced
migration

Climate-induced increase
in storm and flood disasters

Source: Schubert et al. 2007, Figure 8.1-3

Figure 24. Climate Change and Instability Hotspots

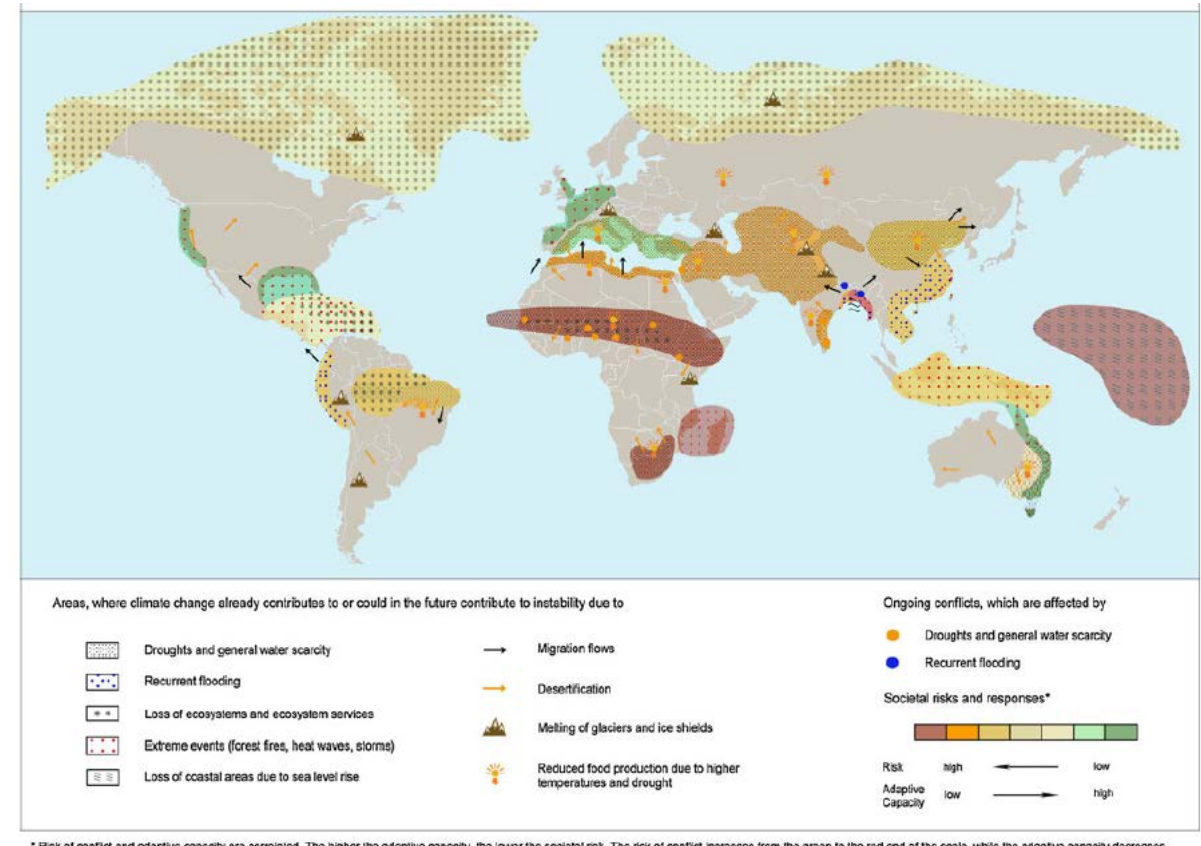

Source: Scheffran and Battaglini 2011, Figure 2. 